\title{
Plasmonic photocatalyst-like fluorescent proteins for generating reactive oxygen species
}

\author{
Jung Woo Leem¹, Seong-Ryul Kim², Kwang-Ho Choi² and Young L. Kim 1,3,4* (D)
}

\begin{abstract}
The recent advances in photocatalysis have opened a variety of new possibilities for energy and biomedical applications. In particular, plasmonic photocatalysis using hybridization of semiconductor materials and metal nanoparticles has recently facilitated the rapid progress in enhancing photocatalytic efficiency under visible or solar light. One critical underlying aspect of photocatalysis is that it generates and releases reactive oxygen species (ROS) as intermediate or final products upon light excitation or activation. Although plasmonic photocatalysis overcomes the limitation of UV irradiation, synthesized metal/semiconductor nanomaterial photocatalysts often bring up biohazardous and environmental issues. In this respect, this review article is centered in identifying natural photosensitizing organic materials that can generate similar types of ROS as those of plasmonic photocatalysis. In particular, we propose the idea of plasmonic photocatalyst-like fluorescent proteins for ROS generation under visible light irradiation. We recapitulate fluorescent proteins that have Type I and Type II photosensitization properties in a comparable manner to plasmonic photocatalysis. Plasmonic photocatalysis and protein photosensitization have not yet been compared systemically in terms of ROS photogeneration under visible light, although the phototoxicity and cytotoxicity of some fluorescent proteins are well recognized. A comprehensive understanding of plasmonic photocatalyst-like fluorescent proteins and their potential advantages will lead us to explore new environmental, biomedical, and defense applications.
\end{abstract}

Keywords: Plasmonic photocatalysis, Fluorescent proteins, Photosensitization, Reactive oxygen species, Visible light

\section{Introduction}

Photocatalysis has extensively been used in a variety of applications, including energy generation, environment remediation, and biomedicine, as mentioned in numerous review articles on photocatalysis [1-8]. Conventional photocatalysis requires three essential components of a semiconductor photocatalyst, a light source with appropriate wavelengths, and an oxidizing agent (e.g. water or oxygen molecules). In semiconductor photocatalysis, the wide bandgap energy (e.g. 3.0-3.2 eV) of semiconductor photocatalysts intrinsically limits light absorption to only the ultraviolet (UV) region (wavelength of light $\lambda<420 \mathrm{~nm}$ ), which accounts for only about $4 \%$ of the total solar energy. Furthermore, the requirement of UV irradiation is commonly considered as a serious biohazard,

\footnotetext{
*Correspondence: youngkim@purdue.edu

1 Weldon School of Biomedical Engineering, Purdue University, West Lafayette, IN 47907, USA

Full list of author information is available at the end of the article
}

potentially leading to premature aging of the skin, suppression of the immune system, damage to the eyes, and skin cancer [9-12]. Thus, to avoid the use of UV as an activation light source, plasmonic effects of metal nanoparticles (mNPs), such as Au, Ag, and Pt, have been successfully hybridized, resulting in broad and strong light absorption in the visible region [13-16], as summarized in several recent review articles [17-21].

One of the important aspects of photocatalysis is photoinduced production of reactive oxygen species (ROS), which often have direct applications for environment remediation and biomedicine, such as disinfection, water purification, and air purification. Typical semiconductor photocatalysts, such as titanium dioxide $\left(\mathrm{TiO}_{2}\right)$ and zinc oxide $(\mathrm{ZnO})$, were extensively studied for efficient and stable photogeneration of ROS [1-6, 22]. As intermediate or final products, semiconductor photocatalysis generates several different types of ROS, including superoxide anion $\left(\mathrm{O}_{2}^{--}\right)$, singlet oxygen $\left({ }^{1} \mathrm{O}_{2}\right)$, hydrogen peroxide $\left(\mathrm{H}_{2} \mathrm{O}_{2}\right)$, and hydroxyl radical $\left(-\mathrm{OH}^{*}\right)$. Regarding 
ROS produced by plasmonic photocatalysis, $\mathrm{O}_{2}^{--}$and ${ }^{1} \mathrm{O}_{2}$ are typically generated via electron transfer under visible light excitation $[13,14]$. Overall, $\mathrm{O}_{2}^{--}$and ${ }^{1} \mathrm{O}_{2}$ play a key role in electrochemistry and photochemistry related to photocatalysis.

There is always an imperative need for cost-effective, eco-friendly, and nontoxic photocatalytic nanomaterials and their photoexcitation using visible (or solar) light. Although plasmonic photocatalysis overcomes the requirement of UV irradiation, it still has concerns with respect to environmental and biomedical utilizations. For example, nano-sized plasmonic photocatalysts (e.g. $1-100 \mathrm{~nm}$ ) could potentially have hazardous and adverse (e.g. carcinogenic and cytotoxic) biological effects, which often result in the limited utilizations for environmental remediation and biomedicine [23, 24]. Noble metals (e.g. Ag, Au, and Pt) also have some drawbacks, including rarity, high cost, and easy dissolution (especially for $\mathrm{Ag}$ ) upon exposure to air or humidity. In this respect, nontoxic organic photosensitizers (e.g. natural dyes or proteins) could potentially be an excellent alternative to noble mNP-based plasmonic photocatalysts, as photosensitization has a great similarity with visible light-driven plasmonic photocatalysis.

In this review article, we introduce plasmonic photocatalyst-like fluorescent proteins for ROS generation upon visible (or solar) light activation. Several recent review articles have extensively covered photosensitizing molecules found in nature (e.g. porphyrin and chlorophyll) [25-27] and genetically-encoded ROS-generating proteins for cellular functions and redox signaling pathways [28-30]. To the best of our knowledge, a systematic review on ROS photoproduction from fluorescent proteins has not yet been available, compared to plasmonic photocatalysis. First, we briefly describe the basic mechanisms of plasmonic photocatalysis and photosensitization in terms of ROS photogeneration. Second, we review selected photosensitizing proteins that can be compared with plasmonic photocatalytic nanomaterials in a parallel manner. Third, we discuss outlook based on the current state of understanding on ROS utilizations. An enhanced understanding of plasmonic photocatalysis and fluorescent protein photosensitization will allow us to take advantage of ROS generated from light-induced fluorescent proteins for unexplored environmental, biomedical, and defense applications.

\section{Basic mechanisms of plasmonic photocatalysis and photosensitization}

\subsection{Visible light-driven plasmonic photocatalysis}

In general, plasmonic photocatalytic activities involve several different underlying mechanisms of electron and energy transfer depending on excitation energy and light sources, as summarized in the recent review articles [17-21]. The current consensus in the community is that visible light-driven plasmonic photocatalysis is mainly associated with generating two types of $\mathrm{ROS}\left(\mathrm{O}_{2}^{--}\right.$and ${ }^{1} \mathrm{O}_{2}$ ) $[13,14]$. Specifically, ROS generation from visible light-activated plasmonic photocatalysis can be summarized as follows (Fig. 1): In plasmonic photocatalysis using plasmon resonance excited by visible light, an electron transfer process from mNP to the semiconductor occurs at the metal/semiconductor interface. In general, Schottky barrier, which interrupts the electron transfer from $\mathrm{mNP}$ to the semiconductor, is formed at the junction interface between $\mathrm{mNP}$ and the semiconductor in the hybrid nanostructures due to the Fermi level difference between the two different materials. However, an electron can travel to the adjacent semiconductor if the plasmonic excitation energy is higher than Schottky barrier. Such a highly energetic electron is often referred to as a 'hot' electron. As the energetic electron in $\mathrm{mNP}$ migrates to the conduction band $\left(E_{\mathrm{CB}}\right)$ of the semiconductor, this process reduces molecular oxygen $\mathrm{O}_{2}\left({ }^{3} \Sigma_{\mathrm{g}}^{-}\right)$of triplet ground state (i.e. ${ }^{3} \mathrm{O}_{2}$ ) to generate $\mathrm{O}_{2}^{--}$at the semiconductor surface. In the meantime, $\mathrm{mNP}$ can hold the positive hole. The positive hole remained in $\mathrm{mNP}$ further oxidizes the previously produced $\mathrm{O}_{2}^{*-}$ to generate additional ROS of ${ }^{1} \mathrm{O}_{2}$ (i.e. $\left.\mathrm{O}_{2}\left({ }^{1} \Delta_{\mathrm{g}}\right)\right)[13,14]$. As a result, plasmonic photocatalysis can generate and release $\mathrm{O}_{2}^{--}$and ${ }^{1} \mathrm{O}_{2}$ under visible light irradiation.

\subsection{Type I and Type II reactions of photosensitization}

Almost all photosensitizing molecules participate in Type I and/or Type II photoreactions involving the generation of ROS upon light activation (Fig. 2a) [31-34]. Predominant ROS generated by photosensitizers depends on a

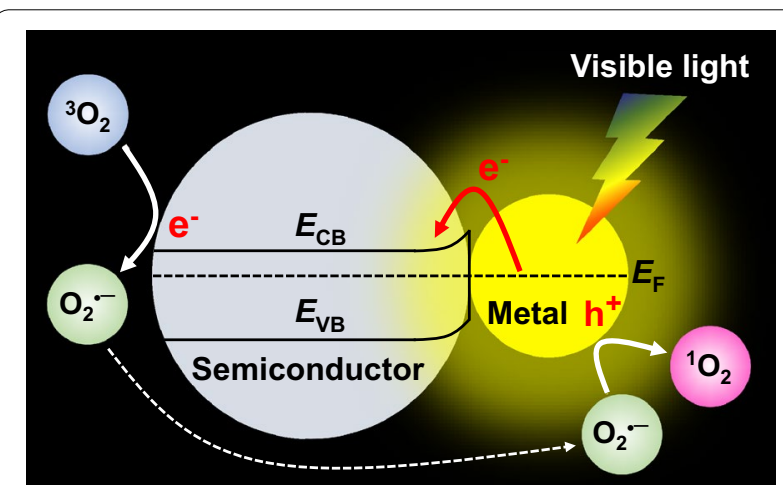

Fig. 1 Schematic illustration of a plausible mechanism for generating $\mathrm{O}_{2}^{--}$and ${ }^{1} \mathrm{O}_{2}$ (i.e. $\mathrm{O}_{2}\left({ }^{1} \triangle_{\mathrm{g}}\right)$ ) on metal-semiconductor hybrid nanostructures via hot electron transfer caused by surface plasmon resonance upon visible light excitation. $E_{\mathrm{CB}}$ and $E_{\mathrm{VB}}$ represent the conduction and valence bands of the semiconductor photocatalyst, respectively. $E_{F}$ refers to the Fermi energy level 


\section{a Photosensitizer}

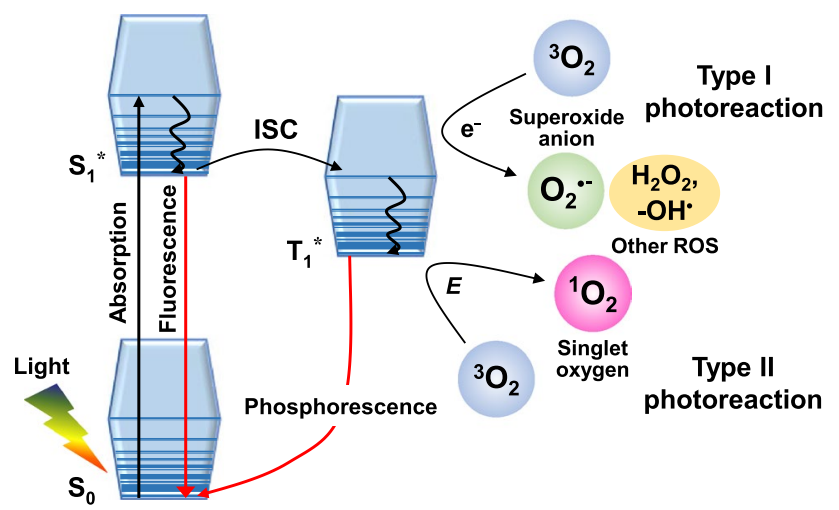

b Molecular oxygen

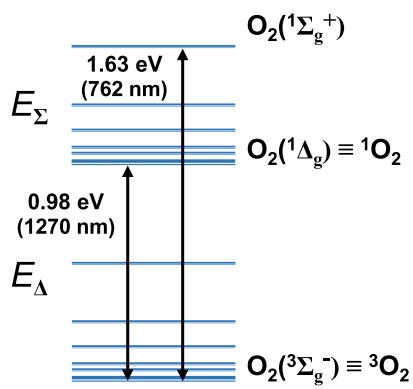

Fig. 2 Jablonski diagram of photosensitizer and molecular oxygen $\left(\mathrm{O}_{2}\right)$. a Photosensitization with the singlet ground $\left(\mathrm{S}_{0}\right)$ and excited $\left(\mathrm{S}_{1}^{*}\right)$ states and their further interactions with $\mathrm{O}_{2}$. The triplet excited state $\left(\mathrm{T}_{1}^{*}\right)$ through an intersystem crossing (ISC) process can undergo electron ( $\mathrm{e}^{-}$) transfer to the ground state of molecular oxygen $\mathrm{O}_{2}\left({ }^{3} \Sigma_{\mathrm{g}}^{-}\right)\left(\mathrm{i} . \mathrm{e} .{ }^{3} \mathrm{O}_{2}\right)$, generating superoxide anion $\left(\mathrm{O}_{2}^{-}\right)$and other ROS products (e.g. $\mathrm{H}_{2} \mathrm{O}_{2}$ and $\left.-\mathrm{OH}^{*}\right)$ as Type I photoreaction. In addition, $\mathrm{T}_{1}^{*}$ can undergo energy $(E)$ transfer to ${ }^{3} \mathrm{O}_{2}$, producing highly cytotoxic $\mathrm{O}_{2}\left({ }^{1} \Delta_{\mathrm{g}}\right)$, commonly known as singlet oxygen $\left({ }^{1} \mathrm{O}_{2}\right)$, as Type II photoreaction. $\mathbf{b}$ Electronic configuration of the triplet ground state molecular oxygen $\mathrm{O}_{2}\left({ }^{3} \Sigma_{\mathrm{g}}^{-}\right.$), its first (i.e. lowest-energy) singlet excited state $\mathrm{O}_{2}\left({ }^{1} \Delta_{g}\right)$, and its second (higher energy) singlet excited state $\mathrm{O}_{2}\left({ }^{1} \Sigma_{g}^{+}\right)[36,37]$, where the superscripts 3 and 1 indicate triplet and singlet states, respectively. The energy gaps between the ground state and the two singlet excited states are shown in eV, including the corresponding luminescent wavelengths

type of photosensitization reactions and a concentration of local electron acceptors. When light is incident on a photosensitizing molecule and light absorption occurs, the molecule is excited from the singlet ground state $\left(\mathrm{S}_{0}\right)$ to the singlet excited state $\left(\mathrm{S}_{1}^{*}\right)$. The excited state loses the energy by returning back to $\mathrm{S}_{0}$ with fluorescent emission or through an intersystem crossing (ISC) process which involves conversion to the long-lived triplet excited state $\left(T_{1}^{*}\right)$. $T_{1}^{*}$ can decay $S_{0}$ via phosphorescent emission or can react with an electron donor molecule. In the latter case, $\mathrm{O}_{2}^{--}$is generated by electron transfer from the substrate in $\mathrm{T}_{1}^{*}$ of the photosensitizer to ${ }^{3} \mathrm{O}_{2}$ as Type I photoreaction. Because the most common electron acceptor is $\mathrm{O}_{2}$, $\mathrm{O}_{2}^{*-}$ can further interact with its surroundings to produce other reactive oxygenated products, such as $\mathrm{H}_{2} \mathrm{O}_{2}$ and $-\mathrm{OH}^{*}$. On the other hand, $\mathrm{T}_{1}^{*}$ can also transfer the energy directly to ${ }^{3} \mathrm{O}_{2}$, producing singlet oxygen of the first (i.e. lowest-energy) singlet excited state ${ }^{1} \mathrm{O}_{2}$ (i.e. $\mathrm{O}_{2}\left({ }^{1} \Delta_{\mathrm{g}}\right)$ ) as Type II photoreaction (Fig. 2b). $\mathrm{O}_{2}\left({ }^{1} \Delta_{\mathrm{g}}\right)$ has energy $(E)$ of $0.98 \mathrm{eV}\left(E_{\Delta}\right)$ and its second (higher energy) singlet excited state $\mathrm{O}_{2}\left({ }^{1} \Sigma_{\mathrm{g}}^{+}\right)$is $1.63 \mathrm{eV}\left(E_{\Delta}+E_{\Sigma}\right)$ above the triplet ground state (i.e. $\left.{ }^{3} \mathrm{O}_{2}\right)$ [35-37]. $\mathrm{O}_{2}\left({ }^{1} \Sigma_{\mathrm{g}}^{+}\right)$decays extremely fast ( $\sim$ picoseconds) to the first excited state ${ }^{1} \mathrm{O}_{2}$ especially in aqueous media by its electronic-to-vibrational energy-transfer process [36-38]. Thus, the generation of $\mathrm{O}_{2}\left({ }^{1} \Sigma_{\mathrm{g}}^{+}\right)$in biology is often neglected. Similarly to visible light-activated plasmonic photocatalysis, Type I and Type II photoreactions of photosensitization can generate and release both $\mathrm{O}_{2}^{--}$and ${ }^{1} \mathrm{O}_{2}$ under visible light activation.

\subsection{ROS lifetime and migration distance in plasmonic photocatalysis and photosensitization}

As explained above, both plasmonic photocatalysis and photosensitization under visible light activation can produce short-lived ROS, given that $\mathrm{O}_{2}^{--}$and ${ }^{1} \mathrm{O}_{2}$ are highly unstable and reactive $[39,40]$. ROS photogenerated from plasmonic photocatalysis and photosensitization is only effective in the vicinity to semiconductor photocatalyst nanomaterials or photosensitizing molecules. Typically, $\mathrm{O}_{2}^{*-}$ exhibits a lifetime of $\sim 50 \mu \mathrm{s}$, depending on the local environments [41]. On the other hand, the typical lifetime of ${ }^{1} \mathrm{O}_{2}$ is $\sim 3.1-3.9 \mu$ s in $\mathrm{H}_{2} \mathrm{O}$. The lifetime of ${ }^{1} \mathrm{O}_{2}$ can be as long as $68 \mu \mathrm{s}$ in deuterium oxide $\left(\mathrm{D}_{2} \mathrm{O}\right)$, because it is mainly determined by energy transfer to the vibrational energy levels of the surrounding molecules [38, 42]. Short-lived ROS from plasmonic photocatalysis and photosensitization allows the migration distance to be as long as $\sim 320$ and $\sim 200 \mathrm{~nm}$ for $\mathrm{O}_{2}^{--}$and ${ }^{1} \mathrm{O}_{2}$, respectively $[41,43]$. Overall, the short lifetime and the relatively short migration (or damage) distance can be considered as a disadvantage requiring a high concentration for a prolonged effect or an advantage for a safeguard, given $\mathrm{O}_{2}^{--}$and ${ }^{1} \mathrm{O}_{2}$ are extremely reactive and toxic.

\section{Identification of phototoxic fluorescent proteins from biological studies}

The phototoxicity and cytotoxicity of some fluorescent proteins are well known in different scientific communities. In cellular imaging, several nontoxic variants of phototoxic fluorescent proteins were successfully developed 
for cellular labeling and imaging in vivo [44-46]. In a contrary manner, phototoxic fluorescent proteins have extensively been employed as a means of selectively damaging target molecules in a localized region and at a particular time-point upon light activation [47-49]. Chromophore photoreduction in red fluorescent proteins (RFPs) is considered to be mainly responsible for photobleaching and phototoxicity, forming dianionic open-shell states of the chromophore in RFPs [50]. This method is known as chromophore-assisted light inactivation (CALI) that can be used to inactivate target cells and ablate tissue of interest. In particular, CALI using fluorescent proteins can allow for spatiotemporal knockdown or loss-of-function of targeted proteins, which can be microscopically controlled with light activation in situ [30, 47, 49, 51]. In addition, some fluorescent proteins can be used for photodynamic therapy (PDT) to destruct diseased tissue without affecting the surrounding healthy tissue [52-54].

CALI and PDT using fluorescent proteins can offer an initial overview to identify major ROS-generating fluorescent proteins. There are several studies on CALI using photosensitizing proteins, such as enhanced green fluorescent protein (EGFP) $[55,56]$, mini Singlet Oxygen Generator (miniSOG) [57], KillerRed [58], and SuperNova [59]. CALI with EGFP was used to inactivate $\alpha$-actinin in fibroblasts, which resulted in stress fiber detachment [55]. EGFP variants, including enhanced yellow fluorescent protein (EYFP) and enhanced cyan fluorescent protein (ECFP), were used for CALI. In general, the efficiency followed an order of EGFP $>$ EYFP $>$ ECFP [56]. The use of miniSOG for CALI was demonstrated [57], in which miniSOG was fused with the succinate dehydrogenase complex subunit of the mitochondrial respiratory complex II to disrupt complex II activity. Mitochondrion-targeted miniSOG caused rapid and effective death of neurons in a cell-autonomous manner without detectable damages to the surrounding cells
[52]. Immunophotosensitizer 4D5 single chain variable fragment (4D5scFv)-miniSOG was used to selectively recognize the extracellular domain of human epidermal growth factor receptor 2 (HER2/neu) [53]. KillerRed was used for CALI of Escherichia coli and eukaryotic cells [58, $60,61]$. KillerRed was also tested for PDT by fusing to an antibody to target tumor cells, resulting in tumor-specific cell death [54]. SuperNova, which is a monomeric variant of KillerRed, was used to suppress actin filament motility by illuminating orange light [59].

\section{ROS photogeneration of phototoxic fluorescent proteins}

The main underlying mechanism by which the aforementioned fluorescent proteins are phototoxic and cytotoxic is that these proteins are capable of generating and releasing several different types of ROS. The optical absorption and emission of phototoxic fluorescent proteins and their detected ROS types are summarized in Table 1. To the best of our knowledge, this table provides a comprehensive list of phototoxic fluorescent proteins that can generate and release ROS upon visible light excitation and activation in a comparable manner of visible light-activated plasmonic photocatalysis.

\subsection{GFP and EGFP}

GFP was first discovered by Shimomura et al. [72] as a companion protein to the famous chemiluminescent protein (i.e. aequorin) from Aequorea jellyfish. Since then, GFP has revolutionized cell biology and cellular imaging [73]. As an electron donor, GFP was also utilized for converting light-to-electricity in photodetectors or photovoltaic cells [74-77]. GFP has a unique cylindrical (can)-like shape consisting of an 11 -strand $\beta$-barrel with a single $\alpha$-helical strand containing a chromophore. The GFP chromophore is $p$-hydroxybenzylidene-imidazolinone formed from residues 65-67 and is almost perfectly buried in the center of $\beta$-can (Fig. 3a) $[78,79]$. As far as ROS

Table 1 Optical excitation and emission of phototoxic fluorescent proteins and their detected ROS types

\begin{tabular}{lllll}
\hline Fluorescent protein variant & Excitation maximum $(\mathbf{n m})$ & Emission maximum $(\mathbf{n m})$ & Detected ROS type & References \\
\hline GFP & $395 / 476$ & $503 / 509$ & ${ }^{1} \mathrm{O}_{2}$ & {$[62]$} \\
EGFP & 488 & 507 & $\mathrm{O}_{2}$ & {$[63]$} \\
miniSOG & 448 & 500 & ${ }^{1} \mathrm{O}_{2}$ & {$[64,65]$} \\
SOPP & 439 & $488 / 515$ & ${ }^{1} \mathrm{O}_{2}$ & {$[66]$} \\
Pp2FbFP L30 M & 449 & 495 & ${ }^{1} \mathrm{O}_{2}$ & {$[67]$} \\
KillerRed & 585 & 610 & $\mathrm{O}_{2}^{-}$and ${ }^{1} \mathrm{O}_{2}$ & {$[59,68,69]$} \\
SuperNova & 579 & 610 & $\mathrm{O}_{2}^{-}$and ${ }^{1} \mathrm{O}_{2}$ & {$[59]$} \\
TagRFP & 555 & 584 & ${ }^{1} \mathrm{O}_{2}$ & {$[70]$} \\
mKate2 & 588 & 633 & $\mathrm{O}_{2}^{-}$and ${ }^{1} \mathrm{O}_{2}$ & {$[71]$} \\
\hline
\end{tabular}



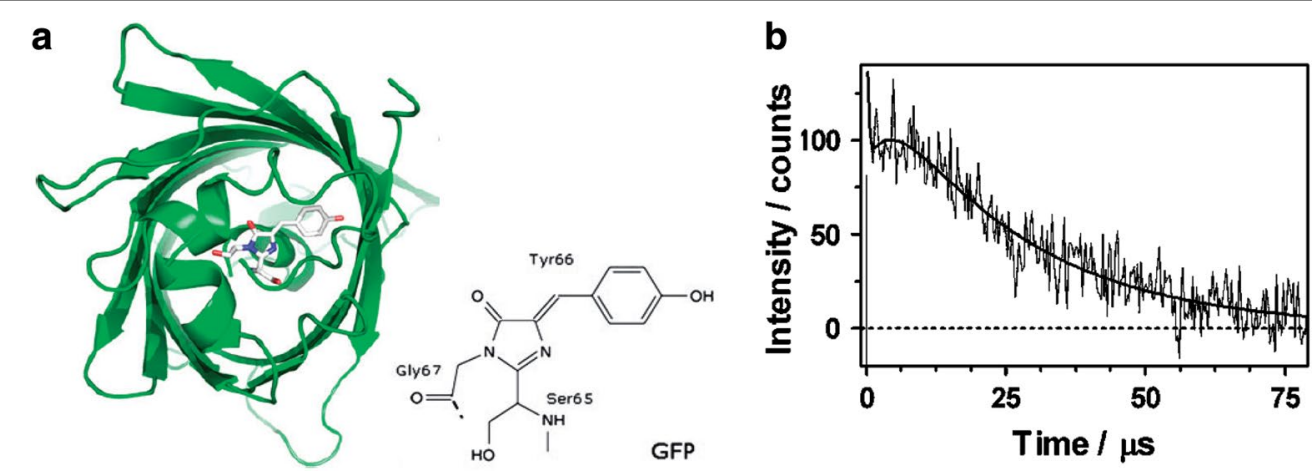

Fig. 3 a 3D structure of GFP (PDB ID: 1GFL) obtained from X-ray crystallography and its mutant Ser65Thr (PDB ID: 1EMA). GFP has a $\beta$-barrel structure with the chromophore embedded in its core (Reproduced from [79] with the permission of Royal Society of Chemistry). The chromophore is shown in its neutral form with protonated phenolic oxygen. b Normalized time-resolved phosphorescent intensity. Emission signals of ${ }^{1} \mathrm{O}_{2}$ generated from EGFP irradiated at $\lambda_{\text {ex }}=532 \mathrm{~nm}$ in deuterated phosphate-buffered saline (d-PBS) (1:3) were detected at $\lambda=1275 \mathrm{~nm}$ (Reproduced from [63] with the permission of Elsevier)

is concerned, GFP and EGFP are typically known to produce ${ }^{1} \mathrm{O}_{2}$ via Type II photoreaction under excitation at blue light of $\lambda=400-500 \mathrm{~nm}[62,63]$. In particular, ${ }^{1} \mathrm{O}_{2}$ production ability of GFP is considered to attribute to the accessibility of molecular oxygen to the chromophore [80]. ${ }^{1} \mathrm{O}_{2}$ was detected in GFP-expressing Escherichia coli bacteria and kidney cells by means of electron spin resonance (ESR); singlet oxygen spin-trap 2,2,6,6-tetramethyl-4-piperidinyloxy (TEMP) was bound to ${ }^{1} \mathrm{O}_{2}$ to produce a stable secondary radical 2,2,6,6-tetramethylpiperidine-1-oxyl (TEMPO) and the TEMPO quantities were measured to correlate with the concentration of ${ }^{1} \mathrm{O}_{2}$ by measuring ESR spectra [62]. ${ }^{1} \mathrm{O}_{2}$ produced by EGFP in a solution was also measured by time-resolved nearinfrared luminescence measurements at $\lambda=1275 \mathrm{~nm}$ (Fig. 3b) [63].

\section{2 minisOG}

By engineering the light-oxygen-voltage (LOV) domain of Arabidopsis thaliana phototropin 2 (AtPhot2), fluorescent flavoprotein miniSOG was originally developed to improve correlative light and electron microscopy $[64,65]$. In terms of sizes (number of amino acids), miniSOG contains 106 amino acids, which is less than half the size of GFP (Fig. 4a). miniSOG is excited maximally at $\lambda_{\mathrm{ex}}=448 \mathrm{~nm}$ and emits green light with two peaks at $\lambda_{\mathrm{em}}=500$ and $528 \mathrm{~nm}$ [64]. Regarding ${ }^{1} \mathrm{O}_{2}$ photogenerated from miniSOG, ${ }^{1} \mathrm{O}_{2}$ was detected using anthracene-9,10-dipropionic acid (ADPA) as a turn-off sensor probe of ${ }^{1} \mathrm{O}_{2}$ [64] and ${ }^{1} \mathrm{O}_{2}$ phosphorescent signals (Fig. 4b, c) [65]. After ADPA reacted with ${ }^{1} \mathrm{O}_{2}$, it was converted to an endoperoxide form, which led to a decrease in fluorescence at $\lambda_{\mathrm{em}}=406 \mathrm{~nm}$ [81]. ${ }^{1} \mathrm{O}_{2}$ photogeneration of miniSOG is also supported the idea that the chromophore is accessible to oxygen molecules [82].
In addition, as an improved mutant of miniSOG, singlet oxygen photosensitizing protein (SOPP) was developed to achieve more efficient photogeneration of ${ }^{1} \mathrm{O}_{2}$ [66].

\subsection{Pp2FbFP L30 M}

Pp2FbFP L30 M was derived from Pseudomonas putida flavin-binding Pp2FbFP with a further mutation of L30 M, which was originated from blue-light photoreceptors of the LOV family [67]. Upon light excitation, ${ }^{1} \mathrm{O}_{2}$ photoproduction of Pp2FbFP L30 M was detected by measuring phosphorescent emission of ${ }^{1} \mathrm{O}_{2}$ at $\lambda_{\mathrm{em}}=1275 \mathrm{~nm}$ (Fig. 5) [67].

\subsection{KillerRed}

KillerRed is one of the most studied RFPs for phototoxicity and ROS photogeneration. Regarding its origin, KillerRed was derived from the jellyfish chromoprotein anm2CP [84]. KillerRed is composed of 11 anti-parallel $\beta$-sheets that form a barrel structure with a central chromophore of Q65-Y66-G67 [85, 86]. Owing to its efficient ROS photogeneration, KillerRed was reported to be strongly phototoxic upon light illumination in a wavelength range of $\lambda_{\text {ex }}=540-580 \mathrm{~nm}[50,68]$, exceeding other fluorescent proteins at least 1000-fold [84]. The extremely high phototoxicity is considered to be mainly attributed from a unique (cleft-like) structural feature in the $\beta$-barrel frame between $\beta 7$ and $\beta 10$ sheets. This cleft-like structure has an opening channel filled with water (oxygen) molecules connecting the chromophore's cavity with the exterior of the protein barrel [84-86] (Fig. 6a). The opening channel leading to the chromophore is considered to facilitate water and/or oxygen diffusion to/from the chromophore. Computational simulations also support the idea that the water channel can increase the chromophore's accessibility to molecular oxygen (Fig. 6b) [86]. 

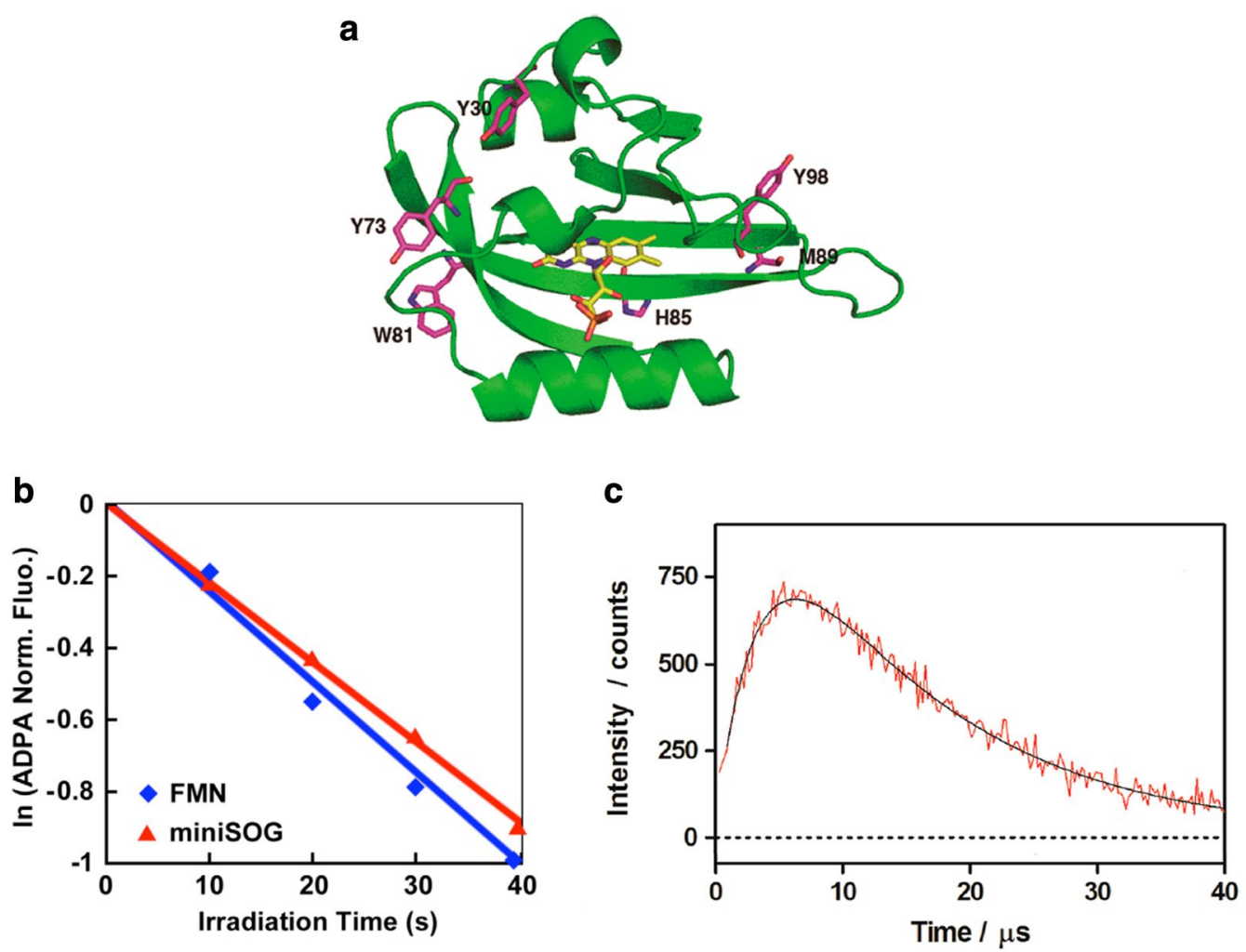

Fig. 4 a 3D structure of miniSOG. This molecular model is based on the structure of the improved LOV protein (PBD ID: 4eet) using the Swiss-model server [83]. The backbone of miniSOG is shown as the green ribbon, flavin mononucleotide (FMN) as the orange sticks, and the amino acids as the magenta sticks (Reproduced from [65] with the permission of American Chemical Society). b Degradation of ADPA reacted with ${ }^{1} \mathrm{O}_{2}$ photogenerated by miniSOG under light irradiation (red) (Figure from [64] and Creative Commons license). c Photosensitized ${ }^{1} \mathrm{O}_{2}$ formation from miniSOG. Time-resolved ${ }^{1} \mathrm{O}_{2}$ phosphorescent signals at $\lambda=1275 \mathrm{~nm}$ were recorded in d-PBS upon pulsed laser excitation at $\lambda_{\mathrm{ex}}=355 \mathrm{~nm}$ (Reproduced from [65] with the permission of American Chemical Society)

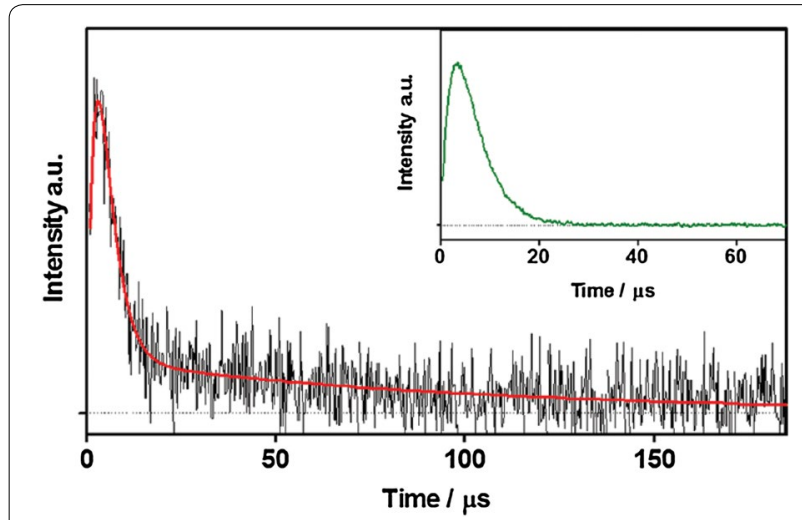

Fig. 5 Time-resolved ${ }^{1} \mathrm{O}_{2}$ phosphorescent signals for Pp2FbFP L30 M $\left(\lambda_{\mathrm{ex}}=355 \mathrm{~nm}\right)$ in an air-saturated PBS solution at $\lambda=1275 \mathrm{~nm}$. The corresponding trace for FMN was included in the inset for comparison to show the absence of the long-lived tail (Reproduced from [67] with the permission of Royal Society of Chemistry)
As far as ROS photogeneration is concerned, KillerRed is known to undergo Type I photosensitization reaction to yield $\mathrm{O}_{2}^{--}$[68]. Irradiated KillerRed exhibited a tenfold increase in fluorescence signals $\left(\lambda_{\text {em }}=440 \mathrm{~nm}\right)$ of 4-((9-acridinecarbonyl)amino)-2,2,6,6-tetramethylpiperidin-1-oxyl (TEMPO-9-ac), compared to unchanged levels of controls (Fig. 6c) [68]. As a turn-on fluorescent free radical probe for sensing ROS related Type I photosensitization, the original status of TEMPO-9-ac is not fluorescent as the acridine moiety is initially quenched by the stable paramagnetic nitroxide moiety. ROS (mostly longlived carbon- or sulfur-centered) can convert nitroxide to the corresponding piperidine, resulting in fluorescence turn-on $\left(\lambda_{\mathrm{ex}}=358 \mathrm{~nm}\right.$ and $\left.\lambda_{\mathrm{em}}=440 \mathrm{~nm}\right)[68,87$, 88]. Irradiated KillerRed with 5,5-dimethyl-1-pyrroline-N-oxide (DMPO) in PBS showed a broad singlet with a peak-to-trough width of 15 Gauss in the electron paramagnetic resonance (EPR) spectrum, supporting 


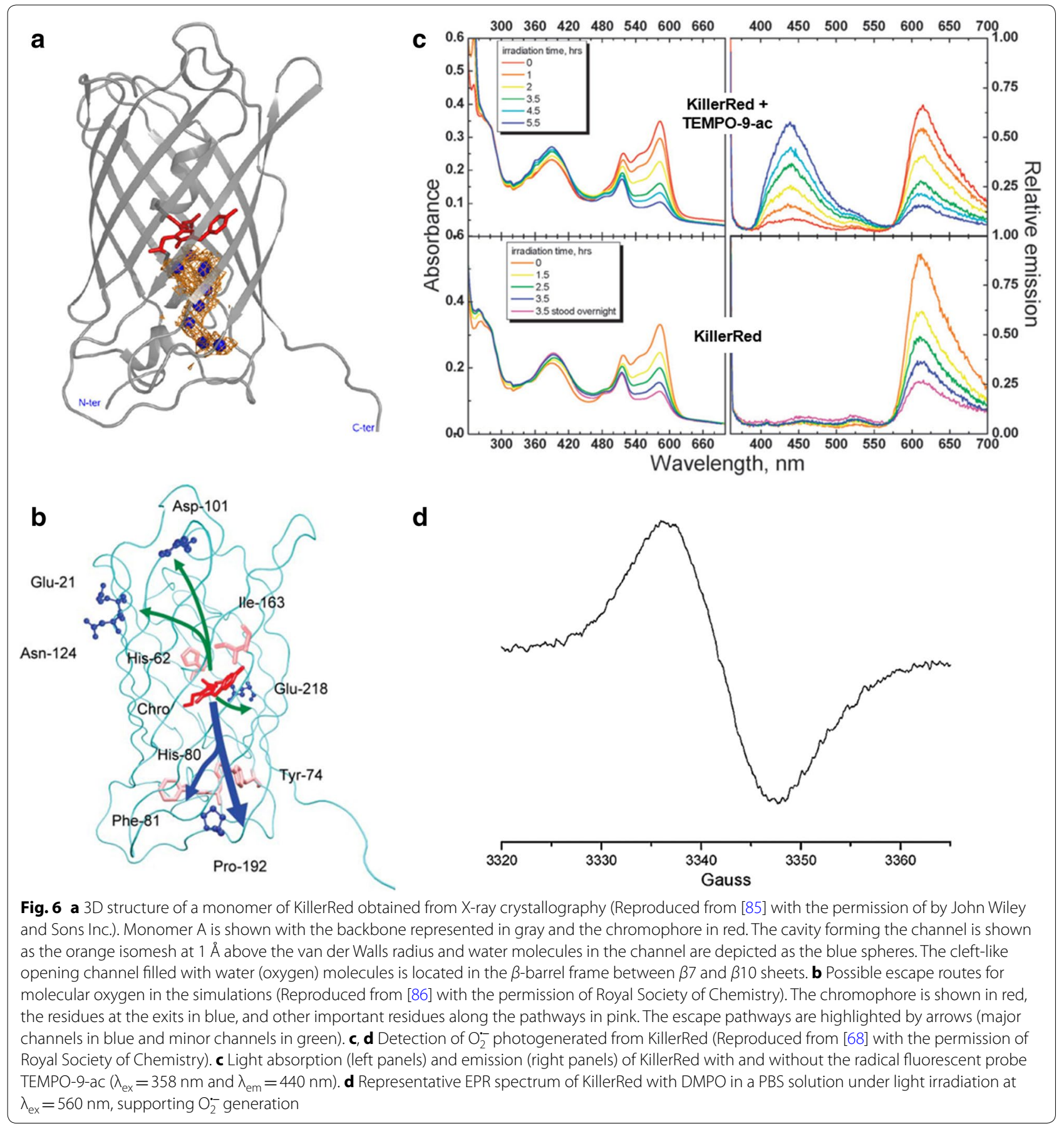

$\mathrm{O}_{2}^{*-}$ generation. (Fig. 6d). As controls, non-irradiated KillerRed and irradiated PBS did not produce EPR signals [68]. ROS associated with Type I photosensitization reaction was also detected with spin trapping of DMPO using steady-state EPR $[89,90]$. In addition to $\mathrm{O}_{2}^{*-},{ }^{1} \mathrm{O}_{2}$ was detected in irradiated KillerRed using a radical scavenger (sodium azide, $\mathrm{NaN}_{3}$ ) and a fluorescent probe (ADPA) $[59,69]$. Thus, ROS photoinduced by KillerRed is primarily associated to $\mathrm{O}_{2}^{--}$with a possibility of ${ }^{1} \mathrm{O}_{2}$ photogeneration.

\subsection{SuperNova}

SuperNova is a monomeric mutant of KillerRed. When KillerRed is fused to a protein of interest, it usually disrupts function and localization of other proteins due to its larger size and functional dimerization. To overcome this 


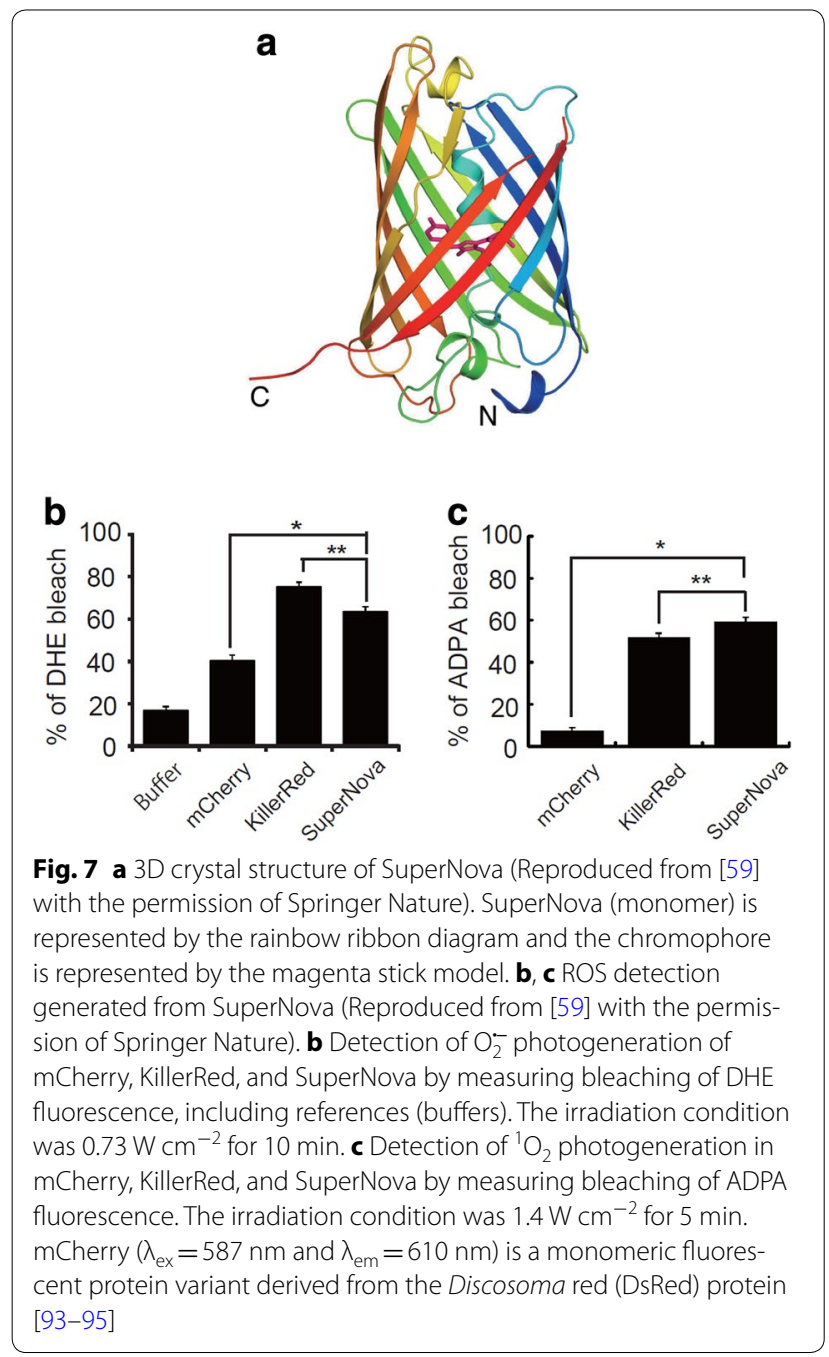

limitation, a monomeric variant was derived from KillerRed via random mutagenesis [59]. Specifically, SuperNova was developed (Fig. 7a), following six mutations compared with KillerRed: G3V, N145S, L160T, F162T, L172 K, M204T [59]. As a result, SuperNova is considered to have the similar photochemical properties as the parental protein (i.e. KillerRed), showing the excitation and emission maxima at $\lambda_{\mathrm{ex}}=579 \mathrm{~nm}$ and $\lambda_{\mathrm{em}}=610 \mathrm{~nm}$, respectively. Both $\mathrm{O}_{2}^{--}$and ${ }^{1} \mathrm{O}_{2}$ generated by SuperNova under orange light irradiation were detected using fluorescent probes of dihydroethidium (DHE) and ADPA, respectively [59]. In particular, enhanced photobleaching in DHE and ADPA supported photogeneration of $\mathrm{O}_{2}^{--}$and ${ }^{1} \mathrm{O}_{2}$ from SuperNova, respectively (Fig. 7b, c) [59]. The original state of DHE exhibits blue fluorescent emission $\left(\lambda_{\mathrm{ex}}=365 \mathrm{~nm}\right.$ and $\left.\lambda_{\mathrm{em}}=435 \mathrm{~nm}\right)$ until being oxidized primarily by $\mathrm{O}_{2}^{--}$. Oxidation of DHE results in hydroxylation at 2-position forming 2-hydroxyethidium, showing reduced blue fluorescent emission (i.e. bleaching) and increased red fluorescent emission $\left(\lambda_{\mathrm{ex}}=490 \mathrm{~nm}\right.$ and $\left.\lambda_{\mathrm{em}}=590 \mathrm{~nm}\right)[91,92]$.

\subsection{TagRFP}

As a monomeric RFP, TagRFP was derived from the sea anemone Entacmaea quadricolor fluorescent protein TurboRFP (random mutant of eqFP578) (Fig. 8a) [96]. Unlike KillerRed [84, 85] and photosensitizing GFP mutants [80], TagRFP is known not to have a clear channel that connects the chromophore with the outside environment [97]. Thus, an alternative mechanism for oxygen diffusion in TagRFP was suggested such that transient protein permeability can play a role due to dynamical breathing [70]. This mechanism was also supported by the recent molecular dynamics simulations [86], in which the static picture offered by crystallography was explained by monitoring the triplet state. Regarding ROS photogeneration, TagRFP under green light $\left(\lambda_{\text {ex }}=532 \mathrm{~nm}\right)$ produced ${ }^{1} \mathrm{O}_{2}$, which was confirmed by both time-resolved phosphorescence of ${ }^{1} \mathrm{O}_{2}$ and a turn-on fluorescent probe of singlet-oxygen sensor green (SOSG) (Fig. 8b, c), even though $\mathrm{O}_{2}^{--}$was not detected using a fluorescent probe of DHE [70]. Specifically, pulsed laser irradiation $\left(\lambda_{\mathrm{ex}}=532 \mathrm{~nm}\right)$ of TagRFP in an air-saturated mixture of PBS, glycerol, and d-PBS (1:1:20) allowed the detection of ${ }^{1} \mathrm{O}_{2}$ phosphorescence at $\lambda=1270 \mathrm{~nm}$ (Fig. 8b), in which a fast spike in the earlier part of the signal (due to the scattered laser light and the sensitizer fluorescent emission) was followed by a slower rise and decay, corresponding to ${ }^{1} \mathrm{O}_{2}$ kinetics. With the longer irradiation time, the enhanced SOSG fluorescence signals $\left(\lambda_{\mathrm{ex}}=480 \mathrm{~nm}\right.$ and $\left.\lambda_{\mathrm{em}}=527 \mathrm{~nm}\right)$ were also detected (Fig. 8c). Green fluorescent emission of SOSG corresponds to endoperoxide generated by an interaction of ${ }^{1} \mathrm{O}_{2}$ with the anthracene component of SOSG $[98,99]$.

\section{7 mKate2}

mKate2 is a far-red monomeric fluorescent protein with the maximal excitation wavelength $\left(\lambda_{\text {ex }}=588 \mathrm{~nm}\right)$ and emission wavelength $\left(\lambda_{\mathrm{em}}=633 \mathrm{~nm}\right)$, which was derived from mKate containing three mutations of S165A, V48A, and K238R [100]. The mutation of S165A increases the fluorescent brightness, while the mutations of V48A and $\mathrm{K} 238 \mathrm{R}$ accelerate protein maturation, including enhanced $\mathrm{pH}$ stability and photostability. Both mKate and mKate 2 are widely considered as one of the phototoxic fluorescent proteins [44, 101], because of a cleft-like opening channel filled with water (oxygen) molecules in the $\beta$-barrel frame between $\beta 7$ and $\beta 10$ (Fig. 9a) [102]. ROS generated from mKate 2 embedded in silk (i.e. RFP fluorescent silk produced from silkworm transgenesis [71, 103]) under green light irradiation $(\lambda=532 \mathrm{~nm})$ was detected using fluorescent probes of TEMPO-9-ac 

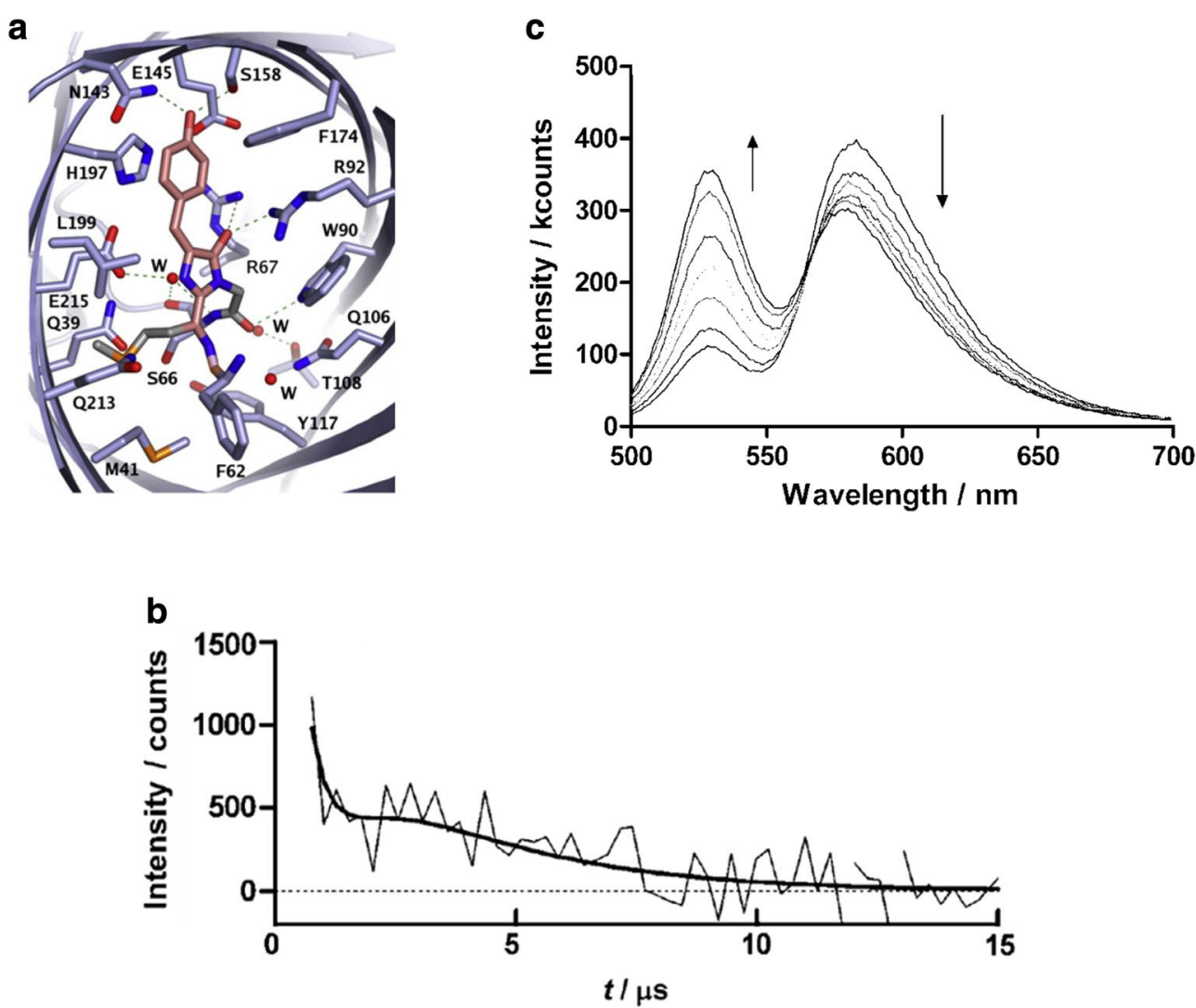

Fig. 8 a Chromophore and their environment in TagRFP (Reproduced from [97] with the permission of Elsevier). The chromophore backbone for TagRFP is shown in orange. The hydrogen bonds are indicated with the green dashed lines, the atoms are colored by the atom type, and the water molecules are shown as the red spheres. b, $\mathbf{c}$ Detection of ${ }^{1} \mathrm{O}_{2}$ photogenerated from TagRFP (Reproduced from [70] with the permission of John Wiley and Sons). $\mathbf{b}^{1} \mathrm{O}_{2}$ phosphorescence photosensitized by TagRFP in a PBS:Glycerol:d-PBS mixture (1:1:20) upon irradiation at $\lambda_{\text {ex }}=532 \mathrm{~nm}$. The luminescence signal at $\lambda=1270 \mathrm{~nm}$ was fit with a triexponential function. $\mathbf{c}$ Time course of fluorescent spectra of optically matched solutions of SOSG $\left(\lambda_{\text {ex }}=480 \mathrm{~nm}\right)$ and TagRFP under light irradiation at $\lambda_{\text {ex }}=532 \mathrm{~nm}$. The increased amount of ${ }^{1} \mathrm{O}_{2}$ was detected by the increase in the SOSG band $\left(\lambda_{\mathrm{em}}=527 \mathrm{~nm}\right)$ with irradiation at $\lambda_{\mathrm{ex}}=532 \mathrm{~nm}$. The concomitant decrease in the TagRFP band $\left(\lambda_{\mathrm{em}}=590 \mathrm{~nm}\right)$ indicated photobleaching and/ or photoconversion

and 9,10-anthracenediyl-bis(methylene)dimalonic acid (ABDA) for $\mathrm{O}_{2}^{--}$and ${ }^{1} \mathrm{O}_{2}$, respectively (Fig. 9b, c) [71]. As the irradiation time of green light increased, the intensity of TEMPO-9-ac fluorescent peaks gradually enhanced and the ABDA fluorescent intensity decreased, compared to the baseline signals before light irradiation (controls). These result support the photogeneration of $\mathrm{O}_{2}^{--}$and ${ }^{1} \mathrm{O}_{2}$ from mKate2. Similarly, ABDA was also widely used to detect the formation of ${ }^{1} \mathrm{O}_{2}$ in solutions [71, 104, 105]; the original state of ABDA emits fluorescence at $\lambda_{\mathrm{em}}=431 \mathrm{~nm}$ under photoexcitation at $\lambda_{\mathrm{ex}}=380 \mathrm{~nm}$ and the oxidation of ABDA by ${ }^{1} \mathrm{O}_{2}$ creates an endoperoxide, resulting in reduced fluorescent intensity [104].

\subsection{Fluorescent proteins with a cleft-like structure in $\beta$-barrels}

Besides the aforementioned fluorescent proteins including KillerRed [85, 86] and mKate/mKate2 [71, 102], other fluorescent proteins could potentially be efficient in generating and releasing ROS upon visible light irradiation. As excellent candidates, several fluorescent proteins are known to contain a cleft-like water-filled channel in the $\beta$-barrel frame. Excellent examples include DronPa [106], TurboGFP [107], mCherry [95], KillerOrange/ mKillerOrange [108], and zGFP506, zYFP538, zRFP574 [109] (Fig. 10). A water channel inside these fluorescent protein is suggested to open up solvent access to methylene/imidazolinone moieties of chromophores, allowing for enhanced generation and release of ROS, which in turn results in photobleaching and phototoxicity [44, $85,110]$. The water channel may also facilitate oxygen transport to a premature chromophore. This may promote the dehydrogenation step of chromophore maturation and transport abstracted proton transport outside the $\beta$-barrel, speeding up the chromophore's maturation [107]. Indeed, ROS release from the fluorescent protein's 

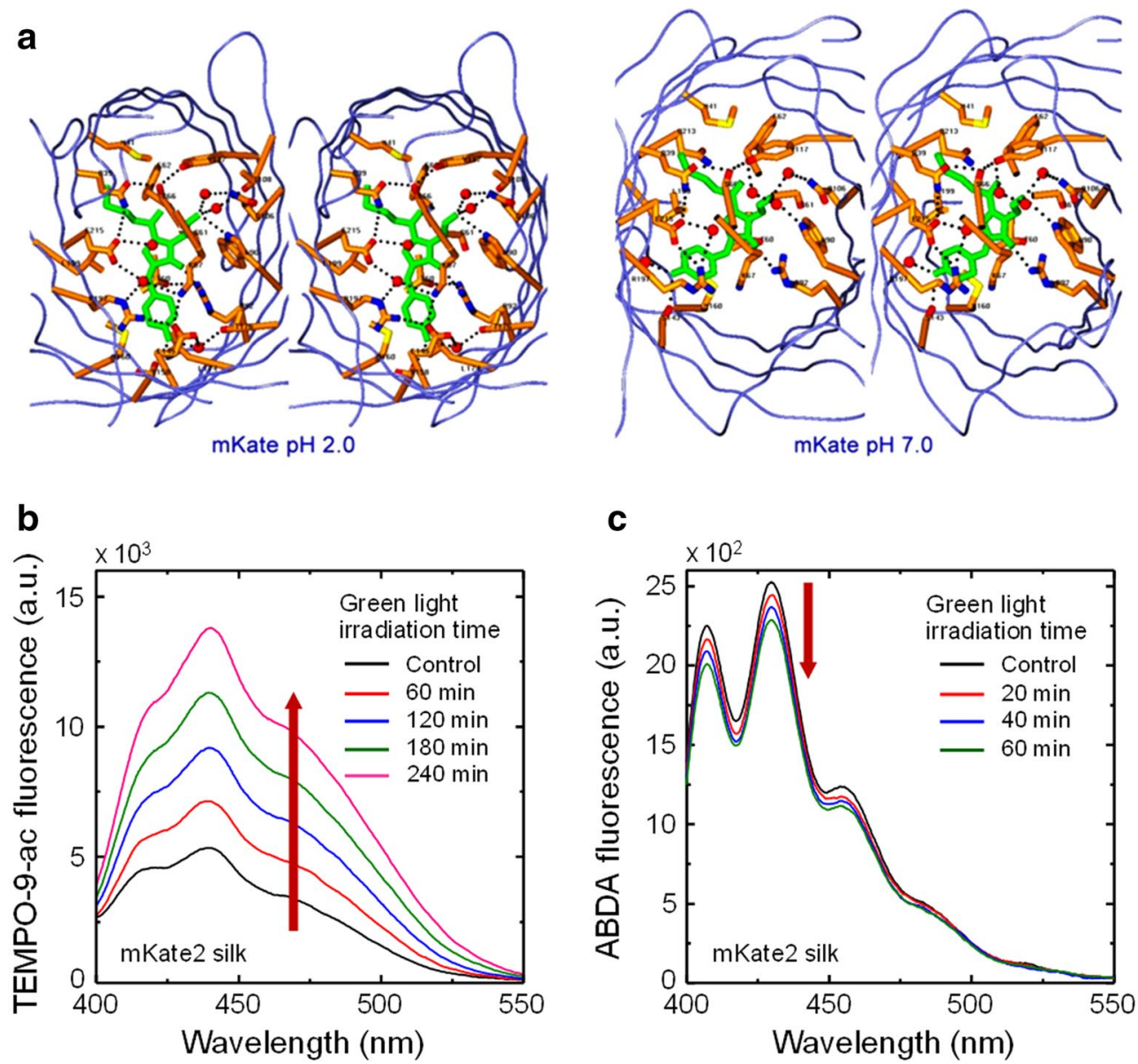

Fig. 9 a 3D structure of the H-bond network in the vicinity of the trans chromophore (shown in green) for the mKate_pH2.0 structure (left) and the cis chromophore in the mKate_pH7.0 structure (right). Mediating waters are shown by red spheres (Reproduced from [102] with the permission of American Society for Biochemistry and Molecular Biology). b, c Detection of ROS generated by mKate2 embedded in silk (i.e. RFP fluorescent silk produced from silkworm transgenesis) using turn-on/off fluorescent probes upon green light irradiation at $\lambda_{\mathrm{ex}}=532 \mathrm{~nm}$ [71]. Fluorescent emission signals of the probes were monitored from solutions containing mKate2 fluorescent silk. $\mathbf{b} \mathrm{O}_{2}^{-}$mediated by Type I photosensitization reaction, captured by turn-on fluorescent signals of TEMPO-9-ac $\left(\lambda_{\mathrm{ex}}=365 \mathrm{~nm}\right) \cdot \mathbf{c}^{1} \mathrm{O}_{2}$ mediated by Type II photosensitization reaction, detected by reduction in the original ABDA fluorescent intensity $\left(\lambda_{\text {ex }}=365 \mathrm{~nm}\right)$

$\beta$-barrel through the water-filled channel may explain some phototoxicity and adverse effects (e.g. inhibition of cell division) of other fluorescent proteins in cellular imaging. Overall, these phototoxic fluorescent proteins warrant further detailed detection studies on photoinduced ROS and their exact types.

\section{Outlook and conclusion}

We have discussed the similarities between plasmonic photocatalysis and phototoxic fluorescent proteins in terms of ROS generation under visible light activation. Like plasmonic photocatalysis, protein photosensitization requires three essential components of a fluorescent protein, a light source with appropriate wavelengths, and an oxidizing agent. A proper interaction of these elements leads to the photogeneration of ROS in the close vicinity. Among the current active applications in environment remediation and biomedicine, $\mathrm{O}_{2}^{--}$and/ or ${ }^{1} \mathrm{O}_{2}$ photogeneration from fluorescent proteins could highly be useful for inactivating harmful microorganisms and pathogens, such as bacteria, viruses, and fungi [111, 112], as well as contaminants and endocrine disrupting compounds [113]. In particular, ROS (i.e. ${ }^{1} \mathrm{O}_{2}$ ) can be effective in inactivating viruses, impairing genome replication [114-117]. ROS could be useful for insect eradication $[118,119]$ and water disinfection for control of water-borne pathogens $[120,121]$.

Protein photosensitization can offer several pivotal advantages over conventional photocatalysis: (i) Fluorescent proteins can rule out biohazardous concerns on the 
a

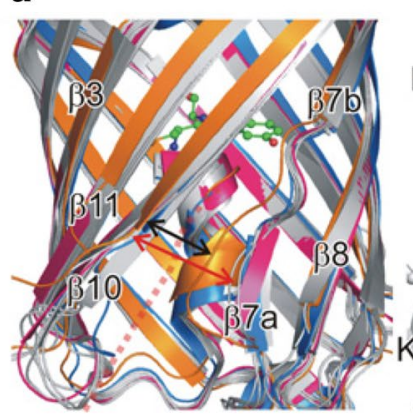

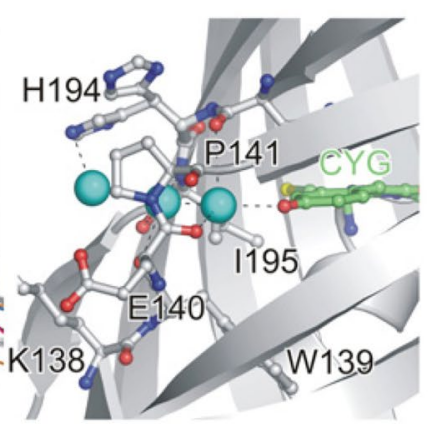

b

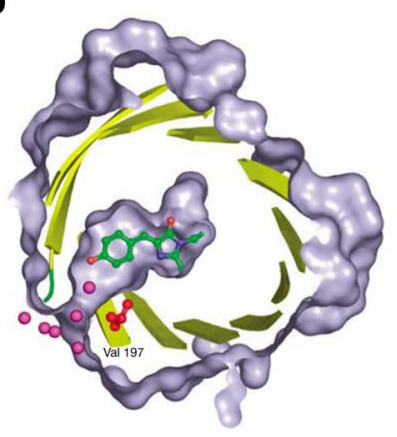

C

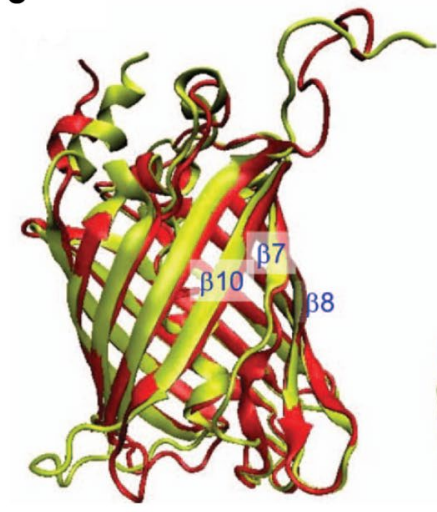

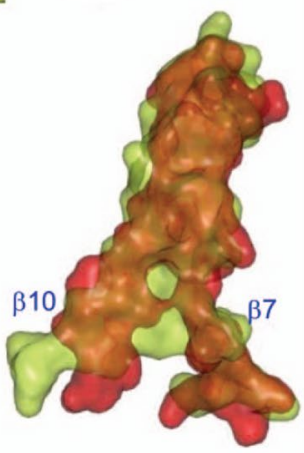

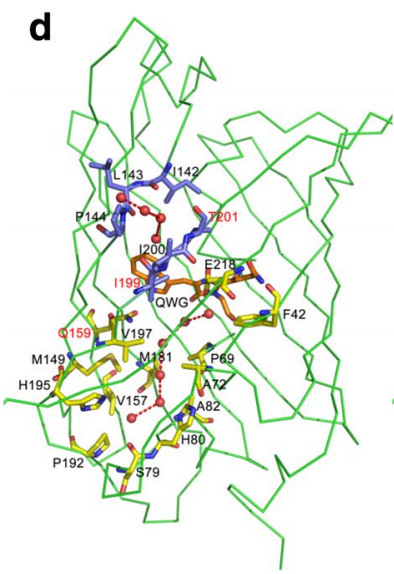

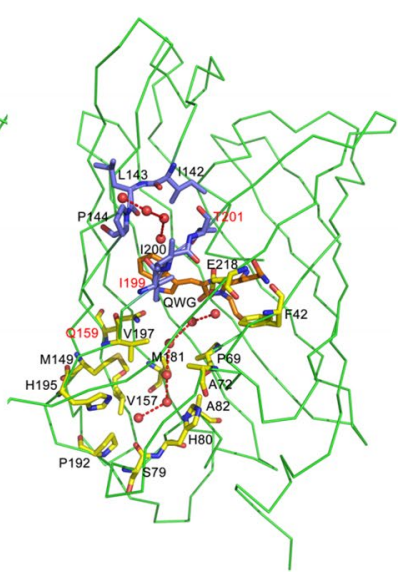

Fig. 10 Cleft-like channels filled with water (oxygen) molecules in the $\beta$-barrel frame between $\beta 7$ and $\beta 10$ sheets of DronPa (a) (Reproduced from [106] with the permission of Portland Press Ltd.), TurboGFP (b) (Reproduced from [107] with the permission of John Wiley and Sons), mCherry (c) (Reproduced from [95] with the permission of AIP Publishing LLC.), and KillerOrange/mKillerOrange (d) (Figure from [108] and Creative Commons license). a DronPa: The cleft (indicated by the broken line) near to strand $\beta 7$ is conserved. The red double headed arrow indicates the width of the cleft. Water molecules are shown as the cyan spheres, building hydrogen-bonded connection between the chromophore and the aqueous environment. The protein region around the opening and the chromophore is shown as the ball-and-stick model. b TurboGFP: A pore leading to the TurboGFP chromophore. The chromophore is highlighted in green and Val 197 in red. The protein surface (gray) is cut to show the pore and the chromophore cavity. The sections of secondary structure elements are shown as the yellow cartoons. Relevant water molecules are depicted as the magenta spheres. c mCherry: The superposition of ribbon structures of red (mCherry) and yellow (citrine) fluorescent proteins. The $\beta 7-\beta 10$ region is displayed with a space filling model to show that the gap in mCherry is larger than that in citrine. $\mathbf{d}$ KillerOrange (dimer) and mKillerOrange (monomer): The pore is filled by four water molecules connecting the indole moiety of the chromophore with the protein exterior. The water channel (residues shown in yellow) with a chain of seven water molecules (red spheres) and the pore (residues shown in blue) filled with four water molecules. The residues mutated in this work are labeled in red

byproducts and residuals of foreign synthesized metal/ semiconductor nanomaterial photocatalysts. Thus, fluorescent proteins can overcome the limitation of hazardous and adverse (e.g. carcinogenic and cytotoxic) effects associated with photocatalytic nanoparticles [23, 24]. Fluorescent proteins are degradable and digestible, eliminating the potential risk of exposure and consumption. (ii) Without a need of additional nanoconjugations (e.g. mNPs, photosensitizers, and quantum dots), fluorescent proteins can generate selective ROS by being activated under solar (visible) light without UV irradiation. (iii) As ROS-generating nanomaterials, fluorescent proteins could potentially be mass-produced in an eco-friendly manner using biological reactors (e.g. microorganisms and insects) [71, 103, 122-124].

\section{Authors' contributions}

JWL and YLK mainly wrote the manuscript. All of the authors participated in discussion. All authors read and approved the final manuscript.

\section{Author details}

${ }^{1}$ Weldon School of Biomedical Engineering, Purdue University, West Lafayette, IN 47907, USA. ${ }^{2}$ Department of Agricultural Biology, National Institute of Agricultural Sciences, Rural Development Administration, Wanju, Jeollabuk-do 55365, Republic of Korea. ${ }^{3}$ Regenstrief Center for Healthcare Engineering, West Lafayette, IN 47907, USA. ${ }^{4}$ Purdue Quantum Center, Purdue University, West Lafayette, IN 47907, USA.

\section{Competing interests}

The authors declare that they have no competing interests. 


\section{Consent for publication}

Not applicable.

\section{Ethics approval and consent to participate}

Not applicable.

\section{Funding}

This work was supported by Cooperative Research Program for Agriculture Science \& Technology Development (PJ0120892018) from Rural Development Administration, Republic of Korea and Air Force Office of Scientific Research (FA2386-17-1-4072), USA

\section{Publisher's Note}

Springer Nature remains neutral with regard to jurisdictional claims in published maps and institutional affiliations.

Received: 6 February 2018 Accepted: 6 March 2018

Published online: 22 March 2018

\section{References}

1. J. Schneider, M. Matsuoka, M. Takeuchi, J.L. Zhang, Y. Horiuchi, M. Anpo, D.W. Bahnemann, Understanding $\mathrm{TiO}_{2}$ photocatalysis: mechanisms and materials. Chem. Rev. 114, 9919-9986 (2014)

2. K. Nakata, A. Fujishima, $\mathrm{TiO}_{2}$ photocatalysis: design and applications. J. Photochem. Photobiol. C 13, 169-189 (2012)

3. K. Hashimoto, H. Irie, A. Fujishima, $\mathrm{TiO}_{2}$ photocatalysis: a historical overview and future prospects. Jpn. J. Appl. Phys. 44, 8269-8285 (2005)

4. M. Ni, M.K.H. Leung, D.Y.C. Leung, K. Sumathy, A review and recent developments in photocatalytic water-splitting using $\mathrm{TiO}_{2}$ for hydrogen production. Renew. Sust. Energy Rev. 11, 401-425 (2007)

5. P.C. Maness, S. Smolinski, D.M. Blake, Z. Huang, E.J. Wolfrum, W.A. Jacoby, Bactericidal activity of photocatalytic $\mathrm{TiO}_{2}$ reaction: toward an understanding of its killing mechanism. Appl. Environ. Microbiol. 65 4094-4098 (1999)

6. X.B. Chen, S.H. Shen, L.J. Guo, S.S. Mao, Semiconductor-based photocatalytic hydrogen generation. Chem. Rev. 110, 6503-6570 (2010)

7. H. Kisch, Semiconductor photocatalysis: principles and applications (Wiley-VCH Verlag GmbH \& Co, Weinheim, 2015)

8. D.S. Bhatkhande, V.G. Pangarkar, A.A.C.M. Beenackers, Photocatalytic degradation for environmental applications-A review. J. Chem. Technol. Biotechnol. 77, 102-116 (2002)

9. D.L. Narayanan, R.N. Saladi, J.L. Fox, Ultraviolet radiation and skin cancer. Int. J. Dermatol. 49, 978-986 (2010)

10. F.R. de Gruijl, Skin cancer and solar UV radiation. Eur. J. Cancer $\mathbf{3 5}$ 2003-2009 (1999)

11. B.K. Armstrong, A. Kricker, The epidemiology of UV induced skin cancer. J. Photoch. Photobio. B 63, 8-18 (2001)

12. J. D'Orazio, S. Jarrett, A. Amaro-Ortiz, T. Scott, UV Radiation and the Skin. Int. J. Mol. Sci. 14, 12222-12248 (2013)

13. H. Saito, Y. Nosaka, Mechanism of singlet oxygen generation in visiblelight-induced photocatalysis of gold-nanoparticle-deposited titanium dioxide. J. Phys. Chem. C 118, 15656-15663 (2014)

14. H. Saito, Y. Nosaka, Enhancement of the generation of photocatalytic active species by loading copper ions on gold-nanoparticle-deposited titanium dioxide. Catal. Commun. 61, 117-120 (2015)

15. L.K. Bharat, G. Nagaraju, K.G. Krishna, J.S. Yu, Controlled synthesis of yttrium gallium garnet spherical nanostructures modified by silver oxide nanoparticles for enhanced photocatalytic properties. CrystEngComm 18, 8915-8925 (2016)

16. B. Dudem, L.K. Bharat, J.W. Leem, D.H. Kim, J.S. Yu, Hierarchical Ag/ $\mathrm{TiO}_{2} / \mathrm{Si}$ forest-like nano/micr-architectures as antireflective, plasmonic photocatalytic, and self-cleaning coatings. ACS Sustain. Chem. Eng. 6, 1580-1591 (2017)

17. S. Linic, U. Aslam, C. Boerigter, M. Morabito, Photochemical transformations on plasmonic metal nanoparticles. Nat. Mater. 14, 567-576 (2015)

18. S.V. Boriskina, H. Ghasemi, G. Chen, Plasmonic materials for energy: from physics to applications. Mater. Today 16, 375-386 (2013)
19. X.M. Zhang, Y.L. Chen, R.S. Liu, D.P. Tsai, Plasmonic photocatalysis. Rep. Prog. Phys. 76, 046401 (2013)

20. P. Wang, B.B. Huang, Y. Dai, M.H. Whangbo, Plasmonic photocatalysts: harvesting visible light with noble metal nanoparticles. Phys. Chem. Chem. Phys. 14, 9813-9825 (2012)

21. X.C. Ma, Y. Dai, L. Yu, B.B. Huang, Energy transfer in plasmonic photocatalytic composites. Light-Sci. Appl. 5, e16017 (2016)

22. K.M. Lee, C.W. Lai, K.S. Ngai, J.C. Juan, Recent developments of zinc oxide based photocatalyst in water treatment technology: a review. Water Res. 88, 428-448 (2016)

23. B. Trouiller, R. Reliene, A. Westbrook, P. Solaimani, R.H. Schiestl, Titanium dioxide nanoparticles induce DNA damage and genetic instability in vivo in mice. Cancer Res. 69, 8784-8789 (2009)

24. V.K. Sharma, Aggregation and toxicity of titanium dioxide nanoparticles in aquatic environment-A Review. J. Environ. Sci. Health A 44, 1485-1495 (2009)

25. E.D. Sternberg, D. Dolphin, C. Bruckner, Porphyrin-based photosensitizers for use in photodynamic therapy. Tetrahedron 54, 4151-4202 (1998)

26. A.B. Ormond, H.S. Freeman, Dye sensitizers for photodynamic therapy. Materials 6, 817-840 (2013)

27. S. Lacombe, T. Pigot, Materials for selective photo-oxygenation vs. photocatalysis: preparation, properties and applications in environmental and health fields. Catal. Sci. Technol. 6, 1571-1592 (2016)

28. A.P. Wojtovich, T.H. Foster, Optogenetic control of ROS production. Redox Biol. 2, 368-376 (2014)

29. M. Schieber, N.S. Chandel, ROS function in redox signaling and oxidative stress. Curr. Biol. 24, R453-R462 (2014)

30. K. Jacobson, Z. Rajfur, E. Vitriol, K. Hahn, Chromophore-assisted laser inactivation in cell biology. Trends Cell Biol. 18, 443-450 (2008)

31. W.A. Pryor, Oxy-radicals and related species: their formation, lifetimes, and reactions. Ann. Rev. Physiol. 48, 657-667 (1986)

32. C.C. Winterbourn, Reconciling the chemistry and biology of reactive oxygen species. Nat. Chem. Biol. 4, 278-286 (2008)

33. M.S. Baptista, J. Cadet, P. Di Mascio, A.A. Ghogare, A. Greer, M.R. Hamblin, C. Lorente, S.C. Nunez, M.S. Ribeiro, A.H. Thomas, M. Vignoni, T.M. Yoshimura, Type I and Type II photosensitized oxidation reactions: guidelines and mechanistic pathways. Photochem. Photobiol. 93, 912-919 (2017)

34. C.S. Foote, Definition of type-I and type-II photosensitized oxidation. Photochem. Photobiol. 54, 659 (1991)

35. J. Behler, B. Delley, S. Lorenz, K. Reuter, M. Scheffler, Dissociation of $\mathrm{O}_{2}$ at $\mathrm{Al}(111)$ : the role of spin selection rules. Phys. Rev. Lett. 94, 036104 (2005)

36. A. Blazquez-Castro, Direct ${ }^{1} \mathrm{O}_{2}$ optical excitation: a tool for redox biology. Redox Biol. 13, 39-59 (2017)

37. E. Boix-Garriga, B. Rodriguez-amigo, O. Planas, S. Nonell, in Singlet oxygen: applications in biosciences and nanosciences, vol. 1, ed. by S. Nonell, C. Flors (Royal Society of Chemistry, Cambridge, 2016), p. 25

38. C. Schweitzer, R. Schmidt, Physical mechanisms of generation and deactivation of singlet oxygen. Chem. Rev. 103, 1685-1757 (2003)

39. J. Lee, N. Koo, D.B. Min, Reactive oxygen species, aging, and antioxidative nutraceuticals. Compr. Rev. Food Sci. Food Saf. 3, 21-33 (2004)

40. L.M. Hulten, M. Holmstrom, B. Soussi, Harmful singlet oxygen can be helpful. Free Radic. Biol. Med. 27, 1203-1207 (1999)

41. M.P. Lesser, Oxidative stress in marine environments: biochemistry and physiological ecology. Ann. Rev. Physiol. 68, 253-278 (2006)

42. K. Asada, Production and scavenging of reactive oxygen species in chloroplasts and their functions. Plant Physiol. 141, 391-396 (2006)

43. S. Trashin, V. Rahemi, K. Ramji, L. Neven, S.M. Gorun, K. De Wael, Singlet oxygen-based electrosensing by molecular photosensitizers. Nat. Commun. 8, 16108 (2017)

44. R.L. Strack, D.E. Strongin, D. Bhattacharyya, W. Tao, A. Berman, H.E. Broxmeyer, R.J. Keenan, B.S. Glick, A noncytotoxic DsRed variant for whole-cell labeling. Nat. Methods 5, 955-957 (2008)

45. D.M. Chudakov, M.V. Matz, S. Lukyanov, K.A. Lukyanov, Fluorescent proteins and their applications in imaging living cells and tissues. Physiol. Rev. 90, 1103-1163 (2010)

46. B.N. Smith, B.W. Banfield, C.A. Smeraski, C.L. Wilcox, F.E. Dudek, L.W. Enquist, G.E. Pickard, Pseudorabies virus expressing enhanced green fluorescent protein: a tool for in vitro electrophysiological analysis of 
transsynaptically labeled neurons in identified central nervous system circuits. Proc. Nat. Acad. Sci. USA 97, 9264-9269 (2000)

47. O. Tour, R.M. Meijer, D.A. Zacharias, S.R. Adams, R.Y. Tsien, Genetically targeted chromophore-assisted light inactivation. Nat. Biotechnol. 21, 1505-1508 (2003)

48. Z.J. Zhou, J.B. Song, L.M. Nie, X.Y. Chen, Reactive oxygen species generating systems meeting challenges of photodynamic cancer therapy. Chem. Soc. Rev. 45, 6597-6626 (2016)

49. Y. Sano, W. Watanabe, S. Matsunaga, Chromophore-assisted laser inactivation - towards a spatiotemporal-functional analysis of proteins, and the ablation of chromatin, organelle and cell function. J. Cell Sci. 127, 1621-1629 (2014)

50. R.B. Vegh, K.B. Bravaya, D.A. Bloch, A.S. Bommarius, L.M. Tolbert, M. Verkhovsky, A.I. Krylov, K.M. Solntsev, Chromophore photoreduction in red fluorescent proteins is responsible for bleaching and phototoxicity. J. Phys. Chem. B 118, 4527-4534 (2014)

51. T. Surrey, M.B. Elowitz, P.E. Wolf, F. Yang, F. Nedelec, K. Shokat, S. Leibler, Chromophore-assisted light inactivation and self-organization of microtubules and motors. Proc. Nat. Acad. Sci. USA 95, 4293-4298 (1998)

52. Y.C.B. Qi, E.J. Garren, X.K. Shu, R.Y. Tsien, Y.S. Jin, Photo-inducible cell ablation in Caenorhabditis elegans using the genetically encoded singlet oxygen generating protein miniSOG. Proc. Nat. Acad. Sci. USA 109, 7499-7504 (2012)

53. K.E. Mironova, G.M. Proshkina, A.V. Ryabova, O.A. Stremovskiy, S.A. Lukyanov, R.V. Petrov, S.M. Deyev, Genetically encoded immunophotosensitizer $4 \mathrm{D} 5 \mathrm{scFv}$-miniSOG is a highly selective agent for targeted photokilling of tumor cells in vitro. Theranostics 3, 831-840 (2013)

54. E.O. Serebrovskaya, E.F. Edelweiss, O.A. Stremovskiy, K.A. Lukyanov, D.M. Chudakov, S.M. Deyev, Targeting cancer cells by using an antireceptor antibody-photosensitizer fusion protein. Proc. Nat. Acad. Sci. USA 106 9221-9225 (2009)

55. Z. Rajfur, P. Roy, C. Otey, L. Romer, K. Jacobson, Dissecting the link between stress fibres and focal adhesions by CALI with EGFP fusion proteins. Nat. Cell Biol. 4, 286-293 (2002)

56. M.A. McLean, Z. Rajfur, Z.Z. Chen, D. Humphrey, B. Yang, S.G. Sligar, K. Jacobson, Mechanism of chromophore assisted laser inactivation employing fluorescent proteins. Anal. Chem. 81, 1755-1761 (2009)

57. A.P. Wojtovich, A.Y. Wei, T.A. Sherman, T.H. Foster, K. Nehrke, Chromophore-assisted light inactivation of mitochondrial electron transport chain complex II in caenorhabditis elegans. Sci. Rep. 6, 29695 (2016)

58. M.E. Bulina, K.A. Lukyanov, O.V. Britanova, D. Onichtchouk, S. Lukyanov, D.M. Chudakov, Chromophore-assisted light inactivation (CALI) using the phototoxic fluorescent protein KillerRed. Nat. Protoc. 1, 947-953 (2006)

59. K. Takemoto, T. Matsuda, N. Sakai, D. Fu, M. Noda, S. Uchiyama, I. Kotera, Y. Arai, M. Horiuchi, K. Fukui, T. Ayabe, F. Inagaki, H. Suzuki, T. Nagai, SuperNova, a monomeric photosensitizing fluorescent protein for chromophore-assisted light inactivation. Sci. Rep. 3, 2629 (2013)

60. C. Teh, D.M. Chudakov, K.L. Poon, I.Z. Mamedov, J.Y. Sek, K. Shidlovsky, S. Lukyanov, V. Korzh, Optogenetic in vivo cell manipulation in KillerRedexpressing zebrafish transgenics. BMC Dev. Biol. 10, 110 (2010)

61. K. Jewhurst, M. Levin, K.A. Mclaughlin, Optogenetic control of apoptosis in targeted tissues of Xenopus laevis embryos. J. Cell Death 7, 25-31 (2014)

62. L. Greenbaum, C. Rothmann, R. Lavie, Z. Malik, Green fluorescent protein photobleaching: a model for protein damage by endogenous and exogenous singlet oxygen. Biol. Chem. 381, 1251-1258 (2000)

63. A. Jimenez-Banzo, S. Nonell, J. Hofkens, C. Flors, Singlet oxygen photosensitization by EGFP and its chromophore HBDI. Biophys. J. 94 168-172 (2008)

64. X.K. Shu, V. Lev-Ram, T.J. Deerinck, Y.C. Qi, E.B. Ramko, M.W. Davidson, Y.S. Jin, M.H. Ellisman, R.Y. Tsien, A genetically encoded tag for correlated light and electron microscopy of intact cells, tissues, and organisms. PLoS Biol. 9, e1001041 (2011)

65. R. Ruiz-Gonzalez, A.L. Cortajarena, S.H. Mejias, M. Agut, S. Nonell, C. Flors, Singlet oxygen generation by the genetically encoded tag miniSOG. J. Am. Chem. Soc. 135, 9564-9567 (2013)

66. M. Westberg, M. Bregnhoj, M. Etzerodt, P.R. Ogilby, No photon wasted: an efficient and selective singlet oxygen photosensitizing protein. J. Phys. Chem. B 121, 9366-9371 (2017)
67. J. Torra, A. Burgos-Caminal, S. Endres, M. Wingen, T. Drepper, T. Gensch, R. Ruiz-Gonzalez, S. Nonell, Singlet oxygen photosensitisation by the fluorescent protein Pp2FbFP L30 M, a novel derivative of Pseudomonas putida flavin-binding Pp2FbFP. Photochem. Photobiol. Sci. 14, 280-287 (2015)

68. R.B. Vegh, K.M. Solntsev, M.K. Kuimova, S. Cho, Y. Liang, B.L.W. Loo, L.M. Tolbert, A.S. Bommarius, Reactive oxygen species in photochemistry of the red fluorescent protein "Killer Red". Chem. Commun. 47, 4887-4889 (2011)

69. M.E. Bulina, D.M. Chudakov, O.V. Britanova, Y.G. Yanushevich, D.B. Staroverov, T.V. Chepurnykh, E.M. Merzlyak, M.A. Shkrob, S. Lukyanov, K.A. Lukyanov, A genetically encoded photosensitizer. Nat. Biotechnol. 24, 95-99 (2006)

70. X. Ragas, L.P. Cooper, J.H. White, S. Nonell, C. Flors, Quantification of photosensitized singlet oxygen production by a fluorescent protein. ChemPhysChem 12,161-165 (2011)

71. J.W. Leem, J. Park, S.W. Kim, S.R. Kim, S.H. Choi, K.H. Choi, Y.L. Kim, Green light-activated photoreaction via genetic hybridization of far-red fluorescent protein and silk. Adv. Sci. (2018). DOl: https://doi.org/10.1002/ advs.201700863

72. O. Shimomura, The discovery of aequorin and green fluorescent protein. J. Microsc. Oxf. 217, 3-15 (2005)

73. R.N. Day, M.W. Davidson, The fluorescent protein palette: tools for cellular imaging. Chem. Soc. Rev. 38, 2887-2921 (2009)

74. J.W. Choi, Y.S. Nam, S.J. Park, W.H. Lee, D. Kim, M. Fujihira, Rectified photocurrent of molecular photodiode consisting of cytochrome c/GFP hetero thin films. Biosens. Bioelectron. 16, 819-825 (2001)

75. J.W. Choi, Y.S. Nam, W.H. Lee, D. Kim, M. Fujihira, Rectified photocurrent of the protein-based bio-photodiode. Appl. Phys. Lett. 79, 1570-1572 (2001)

76. K. Deepankumar, A. George, G.K. Priya, M. Ilamaran, N.R. Kamini, T.S. Senthil, S. Easwaramoorthi, N. Ayyadurai, Next generation designed protein as a photosensitizer for biophotovoltaics prepared by expanding the genetic code. ACS Sustain. Chem. Eng. 5, 72-77 (2017)

77. Z.G. Chirgwandi, I. Panas, L.G. Johansson, B. Norden, M. Willander, D. Winkler, H. Agren, Properties of a biophotovoltaic nanodevice. J. Phys. Chem. C 112, 18717-18721 (2008)

78. D.C. Prasher, V.K. Eckenrode, W.W. Ward, F.G. Prendergast, M.J. Cormier, Primary structure of the Aequorea victoria green-rluorescent protein. Gene 111, 229-233 (1992)

79. J.J. van Thor, Photoreactions and dynamics of the green fluorescent protein. Chem. Soc. Rev. 38, 2935-2950 (2009)

80. A. Jimenez-Banzo, X. Ragas, S. Abbruzzetti, C. Viappiani, B. Campanini, C. Flors, S. Nonell, Singlet oxygen photosensitisation by GFP mutants: oxygen accessibility to the chromophore. Photochem. Photobiol. Sci. 9 1336-1341 (2010)

81. M. Qin, H.J. Hah, G. Kim, G.C. Nie, Y.E.K. Lee, R. Kopelman, Methylene blue covalently loaded polyacrylamide nanoparticles for enhanced tumor-targeted photodynamic therapy. Photochem. Photobiol. Sci. 10 832-841 (2011)

82. F.M. Pimenta, R.L. Jensen, T. Breitenbach, M. Etzerodt, P.R. Ogillby, Oxygen-dependent photochemistry and photophysics of "MiniSOG," a protein-encased flavin. Photochem. Photobiol. 89, 1116-1126 (2013)

83. Swiss-model http://swissmodel.expasy.org. Accessed 1 Jan 2018

84. S. Pletnev, N.G. Gurskaya, N.V. Pletneva, K.A. Lukyanov, D.M. Chudakov, V.I. Martynov, V.O. Popov, M.V. Kovalchuk, A. Wlodawer, Z. Dauter, V. Pletnev, Structural basis for phototoxicity of the genetically encoded photosensitizer KillerRed. J. Biol. Chem. 284, 32028-32039 (2009)

85. P. Carpentier, S. Violot, L. Blanchoin, D. Bourgeois, Structural basis for the phototoxicity of the fluorescent protein KillerRed. FEBS Lett. 583, 2839-2842 (2009)

86. A. Roy, P. Carpentier, D. Bourgeois, M. Field, Diffusion pathways of oxygen species in the phototoxic fluorescent protein KillerRed. Photochem. Photobiol. Sci. 9, 1342-1350 (2010)

87. N.V. Blough, D.J. Simpson, Chemically mediated fluorescence yield switching in nitroxide fluorophore adducts-Optical sensors of radical redox reactions. J. Am. Chem. Soc. 110, 1915-1917 (1988)

88. C.A. Cohn, S.R. Simon, M.A.A. Schoonen, Comparison of fluorescencebased techniques for the quantification of particle-induced hydroxyl radicals. Part. Fibre Toxicol. 5, 2 (2008) 
89. G.R. Buettner, The spin-trapping of superoxide and hydroxyl freeradicals with DMPO (5,5-dimethylpyrroline-n-oxide)—more about iron. Free Rad. Res. Commun. 19, S79-S87 (1993)

90. S.L. de Menezes, O. Augusto, EPR detection of glutathionyl and protein-tyrosyl radicals during the interaction of peroxynitrite with macrophages (J774). J. Biol. Chem. 276, 39879-39884 (2001)

91. C. Bucana, I. Saiki, R. Nayar, Uptake and accumulation of the vital dye hydroethidine in neoplastic cells. J. Histochem. Cytochem. 34, 1109-1115 (1986)

92. J.M. Lu, P.H. Lin, Q.Z. Yao, C.Y. Chen, Chemical and molecular mechanisms of antioxidants: experimental approaches and model systems. J. Cell Mol. Med. 14, 840-860 (2010)

93. W.F. van Zyl, S.M. Deane, L.M.T. Dicks, Use of the mCherry fluorescent protein to study intestinal colonization by Enterococcus mundtii ST4SA and Lactobacillus plantarum 423 in mice. Appl. Environ. Microbiol. 81, 5993-6002 (2015)

94. N.C. Shaner, R.E. Campbell, P.A. Steinbach, B.N.G. Giepmans, A.E. Palmer, R.Y.Tsien, Improved monomeric red, orange and yellow fluorescent proteins derived from Discosoma sp. red fluorescent protein. Nat. Biotechnol. 22, 1567-1572 (2004)

95. P.P. Chapagain, C.K. Regmi, W. Castillo, Fluorescent protein barrel fluctuations and oxygen diffusion pathways in mCherry. J. Chem. Phys. 135, 235101 (2011)

96. E.M. Merzlyak, J. Goedhart, D. Shcherbo, M.E. Bulina, A.S. Shcheglov, A.F. Fradkov, A. Gaintzeva, K.A. Lukyanov, S. Lukyanov, T.W.J. Gadella, D.M. Chudakov, Bright monomeric red fluorescent protein with an extended fluorescence lifetime. Nat. Methods 4, 555-557 (2007)

97. O.M. Subach, V.N. Malashkevich, W.D. Zencheck, K.S. Morozova, K.D. Piatkevich, S.C. Almo, V.V. Verkhusha, Structural characterization of acylimine-containing blue and red chromophores in mTagBFP and TagRFP fluorescent proteins. Chem. Biol. 17, 333-341 (2010)

98. C. Flors, M.J. Fryer, J. Waring, B. Reeder, U. Bechtold, P.M. Mullineaux, S. Nonell, M.T. Wilson, N.R. Baker, Imaging the production of singlet oxygen in vivo using a new fluorescent sensor, Singlet Oxygen Sensor Green ${ }^{\circledR}$. J. Exper. Botany 57, 1725-1734 (2006)

99. X. Ragas, A. Jimenez-Banzo, D. Sanchez-Garcia, X. Batllori, S. Nonell, Singlet oxygen photosensitisation by the fluorescent probe Singlet Oxygen Sensor Green ${ }^{\circledR}$. Chem. Commun. 20, 2920-2922 (2009)

100. D. Shcherbo, C.S. Murphy, G.V. Ermakova, E.A. Solovieva, T.V. Chepurnykh, A.S. Shcheglov, V.V. Verkhusha, V.Z. Pletnev, K.L. Hazelwood, P.M. Roche, S. Lukyanov, A.G. Zaraisky, M.W. Davidson, D.M. Chudakov, Far-red fluorescent tags for protein imaging in living tissues. Biochem. J. 418, 567-574 (2009)

101. R.L. Strack, B. Hein, D. Bhattacharyya, S.W. Hell, R.J. Keenan, B.S. Glick, A rapidly maturing far-red derivative of DsRed-Express2 for whole-cell labeling. Biochemistry 48, 8179-8281 (2009)

102. S. Pletnev, D. Shcherbo, D.M. Chudakov, N. Pletneva, E.M. Merzlyak, A. Wlodawer, Z. Dauter, V. Pletnev, A crystallographic study of bright farred fluorescent protein mKate reveals $\mathrm{pH}$-induced cis-trans isomerization of the chromophore. J. Biol. Chem. 283, 28980-28987 (2008)

103. J.W. Leem, S.H. Choi, S.R. Kim, S.W. Kim, K.H. Choi, Y.L. Kim, Scalable and continuous nanomaterial integration with transgenic fibers for enhanced photoluminescence. Mater. Horiz. 4, 281-289 (2017)

104. L.Y. Zeng, L.J. Luo, Y.W. Pan, S. Luo, G.M. Lu, A.G. Wu, In vivo targeted magnetic resonance imaging and visualized photodynamic therapy in deep-tissue cancers using folic acid-functionalized superparamagneticupconversion nanocomposites. Nanoscale 7, 8946-8954 (2015)

105. C.H. Fang, H.L. Jia, S. Chang, Q.F. Ruan, P. Wang, T. Chen, J.F. Wang, (Gold core)/(titania shell) nanostructures for plasmon-enhanced photon harvesting and generation of reactive oxygen species. Energy Environ. Sci. 7, 3431-3438 (2014)

106. A.C. Stiel, S. Trowitzsch, G. Weber, M. Andresen, C. Eggeling, S.W. Hell, S. Jakobs, M.C. Wahl, 1.8 angstrom bright-state structure of the reversibly switchable fluorescent protein Dronpa guides the generation of fast switching variants. Biochem. J. 402, 35-42 (2007)

107. A.G. Evdokimov, M.E. Pokross, N.S. Egorov, A.G. Zaraisky, I.V. Yampolsky, E.M. Merzlyak, A.N. Shkoporov, I. Sander, K.A. Lukyanov, D.M. Chudakov, Structural basis for the fast maturation of Arthropoda green fluorescent protein. EMBO Rep. 7, 1006-1012 (2006)
108. N.V. Pletneva, V.Z. Pletnev, K.S. Sarkisyan, D.A. Gorbachev, E.S. Egorov, A.S. Mishin, K.A. Lukyanov, Z. Dauter, S. Pletnev, Crystal structure of phototoxic orange fluorescent proteins with a tryptophan-based chromophore. PLOS ONE 10, e0145740 (2015)

109. N. Pletneva, V. Pletnev, T. Tikhonova, A.A. Pakhomov, V. Popov, V.I. Martynov, A. Wlodawer, Z. Dauter, S. Pletnev, Refined crystal structures of red and green fluorescent proteins from the button polyp Zoanthus. Acta Crystallogr. D 63, 1082-1093 (2007)

110. K.S. Sarkisyan, O.A. Zlobovskaya, D.A. Gorbachev, N.G. Bozhanova, G.V. Sharonov, D.B. Staroverov, E.S. Egorov, A.V. Ryabova, K.M. Solntsev, A.S. Mishin, K.A. Lukyanov, KillerOrange, a genetically encoded photosensitizer activated by blue and green light. PLOS ONE 10, e0145287 (2015)

111. J.L. Wardlaw, T.J. Sullivan, C.N. Lux, F.W. Austin, Photodynamic therapy against common bacteria causing wound and skin infections. Vet. J. 192, 374-377 (2012)

112. R. Yin, T.H. Dai, P. Avci, A.E.S. Jorge, W.C.M.A. de Melo, D. Vecchio, Y.Y. Huang, A. Gupta, M.R. Hamblin, Light based anti-infectives: ultraviolet C irradiation, photodynamic therapy, blue light, and beyond. Curr. Opin. Pharmacol. 13, 731-762 (2013)

113. R. Fagan, D.E. McCormack, D.D. Dionysiou, S.C. Pillai, A review of solar and visible light active $\mathrm{TiO}_{2}$ photocatalysis for treating bacteria, cyanotoxins and contaminants of emerging concern. Mater. Sci. Semicon. Proc. 42, 2-14 (2016)

114. K.R. Wigginton, B.M. Pecson, T. Sigstam, F. Bosshard, T. Kohn, Virus inactivation mechanisms: impact of disinfectants on virus function and structural integrity. Environ. Sci. Technol. 46, 12069-12078 (2012)

115. R. Nakano, M. Hara, H. Ishiguro, Y.Y. Yao, T. Ochiai, K. Nakata, T. Murakami, J. Kajioka, K. Sunada, K. Hashimoto, A. Fujishima, Y. Kubota, Broad spectrum microbicidal activity of photocatalysis by $\mathrm{TiO}_{2}$. Catalysts $\mathbf{3}$ 310-323 (2013)

116. P. Hajkova, P. Spatenka, J. Horsky, I. Horska, A. Kolouch, Photocatalytic effect of $\mathrm{TiO}_{2}$ films on viruses and bacteria. Plasma Process. Polym. 4, S397-S401 (2007)

117. M.V. Liga, S.J. Maguire-Boyle, H.R. Jafry, A.R. Barron, Q.L. Li, Silica decorated $\mathrm{TiO}_{2}$ for virus inactivation in drinking water-Simple synthesis method and mechanisms of enhanced inactivation kinetics. Environ. Sci. Technol. 47, 6463-6470 (2013)

118. E. Alves, M.A.F. Faustino, M.G.P.M.S. Neves, A. Cunha, H. Nadais, A Almeida, Potential applications of porphyrins in photodynamic inactivation beyond the medical scope. J. Photochem. Photobiol. C 22 , 34-57 (2015)

119. T. Ben Amor, G. Jori, Sunlight-activated insecticides: historical background and mechanisms of phototoxic activity. Insect Biochem. Mol. Biol. 30, 915-925 (2000)

120. R. Bonnett, M.A. Krysteva, I.G. Lalov, S.V. Artarsky, Water disinfection using photosensitizers immobilized on chitosan. Water Res. 40 , 1269-1275 (2006)

121. G. Jori, M. Magaraggia, C. Fabris, M. Soncin, M. Camerin, L. Tallandini, O. Coppellotti, L. Guidolin, Photodynamic inactivation of microbial pathogens: disinfection of water and prevention of water-borne diseases. J. Environ. Pathol. Toxicol. Oncol. 30, 261-271 (2011)

122. D.W. Kim, O.J. Lee, S.W. Kim, C.S. Ki, J.R. Chao, H. Yoo, S.I. Yoon, J.E. Lee, Y.R. Park, H. Kweon, K.G. Lee, D.L. Kaplan, C.H. Park, Novel fabrication of fluorescent silk utilized in biotechnological and medical applications. Biomaterials 70, 48-56 (2015)

123. T. lizuka, H. Sezutsu, K. Tatematsu, I. Kobayashi, N. Yonemura, K. Uchino, K. Nakajima, K. Kojima, C. Takabayashi, H. Machii, K. Yamada, H. Kurihara, T. Asakura, Y. Nakazawa, A. Miyawaki, S. Karasawa, H. Kobayashi, J. Yamaguchi, N. Kuwabara, T. Nakamura, K. Yoshii, T. Tamura, Colored fluorescent silk made by transgenic silkworms. Adv. Funct. Mater. 23, 5232-5239 (2013)

124. F. Teule, Y.G. Miao, B.H. Sohn, Y.S. Kim, J.J. Hull, M.J. Fraser, R.V. Lewis, D.L. Jarvis, Silkworms transformed with chimeric silkworm/spider silk genes spin composite silk fibers with improved mechanical properties. Proc. Nat. Acad. Sci. USA 109, 923-928 (2012) 